\title{
(ADP-ribosyl)hydrolases: structure, function, and biology
}

\author{
Johannes Gregor Matthias Rack, ${ }^{1,3}$ Luca Palazzo, ${ }^{2,3}$ and Ivan Ahel ${ }^{1}$ \\ ${ }^{1}$ Sir William Dunn School of Pathology, University of Oxford, Oxford OX1 3RE, United Kingdom; ${ }^{2}$ Institute for the Experimental \\ Endocrinology and Oncology, National Research Council of Italy, 80145 Naples, Italy
}

\begin{abstract}
ADP-ribosylation is an intricate and versatile posttranslational modification involved in the regulation of a vast variety of cellular processes in all kingdoms of life. Its complexity derives from the varied range of different chemical linkages, including to several amino acid side chains as well as nucleic acids termini and bases, it can adopt. In this review, we provide an overview of the different families of (ADP-ribosyl)hydrolases. We discuss their molecular functions, physiological roles, and influence on human health and disease. Together, the accumulated data support the increasingly compelling view that (ADPribosyl)hydrolases are a vital element within ADP-ribosyl signaling pathways and they hold the potential for novel therapeutic approaches as well as a deeper understanding of ADP-ribosylation as a whole.
\end{abstract}

Posttranslational modifications (PTMs) of proteins provide efficient ways to fine-tune or repurpose protein functions by altering their activities, localization, stability, or interaction networks. PTMs thus allow organisms to adapt rapidly to changes in their environment, including nutrient availability or exposure to chemotoxins, or transition between environments, as in the case of a microbial pathogen entering a host body. Consequently, the function of PTMs can be conceived as expanding the limited genome-encoded proteome-typically only a few thousand proteins - to millions of distinct protein forms.

\section{ADP-ribosylation-intricate and versatile \\ ADP-ribosylation is an ancient PTM and intrinsically links signaling with basic metabolism. The modification is established by the transfer of a single or multiple ADP-ribose (ADPr) unit(s) from the redox cofactor $\beta$-nico- tinamide adenine dinucleotide $\left(\beta-\mathrm{NAD}^{+}\right)$onto a variety of acceptor residues on the target protein (Table 1; Fig. 1).}

[Keywords: macrodomain; ARH3, DraG; catalytic mechanism; structural biology; genome stability; ADP-ribose; ADP-ribosylation; DNA damage; PARG; PARP]

${ }^{3}$ These authors contributed equally to this work.

Corresponding author: ivan.ahel@path.ox.ac.uk

Article published online ahead of print. Article and publication date are online at http://www.genesdev.org/cgi/doi/10.1101/gad.334631.119. Freely available online through the Genes \& Development Open Access option.
Diversification of $\mathrm{NAD}^{+}$signaling is particularly apparent in vertebrata, being linked to evolutionary optimization of $\mathrm{NAD}^{+}$biosynthesis and increased (ADP-ribosyl) signaling (Bockwoldt et al. 2019). ADP-ribosylation is used by organisms from all kingdoms of life and some viruses (Perina et al. 2014; Aravind et al. 2015) and controls a wide range of cellular processes such as DNA repair, transcription, cell division, protein degradation, and stress response to name a few (Bock and Chang 2016; Gupte et al. 2017; Palazzo et al. 2017; Rechkunova et al. 2019). In addition to proteins, several in vitro observations strongly suggest that nucleic acids, both DNA and RNA, can be targets of ADP-ribosylation (Nakano et al. 2015; Jankevicius et al. 2016; Talhaoui et al. 2016; Munnur and Ahel 2017; Munnur et al. 2019).

The ADP-ribosylation reaction is catalyzed by a diverse range of (ADP-ribosyl)transferases (ARTs). Phylogenetically, their catalytic domains are part of the ADP-ribosyl superfamily (Pfam clan CL0084) (Amé et al. 2004) and three main clades are generally distinguished based on their characteristic catalytic motif: (1) the H-H- $\Phi$ clade, containing TRPT1/KtpA (also termed Tpt1); (2) the R-SE clade, containing the cholera toxin-like ARTs (ARTCs); and (3) the H-Y-[EDQ] clade, including the diphtheria toxin-like ARTs (ARTDs) (Aravind et al. 2015). [Sequence motifs are given following the regular expression syntax of the ELM resource (http://www.elm.eu.org; Aasland et al. 2002; Gouw et al. 2018).] Functionally, the majority of ARTs catalyze the transfer of a single ADPr moiety onto an acceptor site, termed mono(ADP-ribosyl)ation (MARylation). For example, ARTCs are mostly argininespecific mono(ADP-ribosyl)transferases with the exception of a small group of guanine-specific ADP-ribosylating toxins found in some cabbage butterfly and shellfish species (Table 1; Takamura-Enya et al. 2001; Nakano et al. 2015; Crawford et al. 2018). ARTDs (including the best characterized class poly(ADP-ribosyl)polymerases [PARPs]) appear to have a comparatively broad target range with acidic (glutamate/aspartate), thiol (cysteine), and hydroxyl (serine/tyrosine)-containing residues among others being described as acceptors (Table 1). Lastly,

(C) 2020 Rack et al. This article, published in Genes \& Development, is available under a Creative Commons License (Attribution 4.0 International), as described at http://creativecommons.org/licenses/by/4.0/. 
Table 1. Précis of the functional versatility of ADP-ribosylation

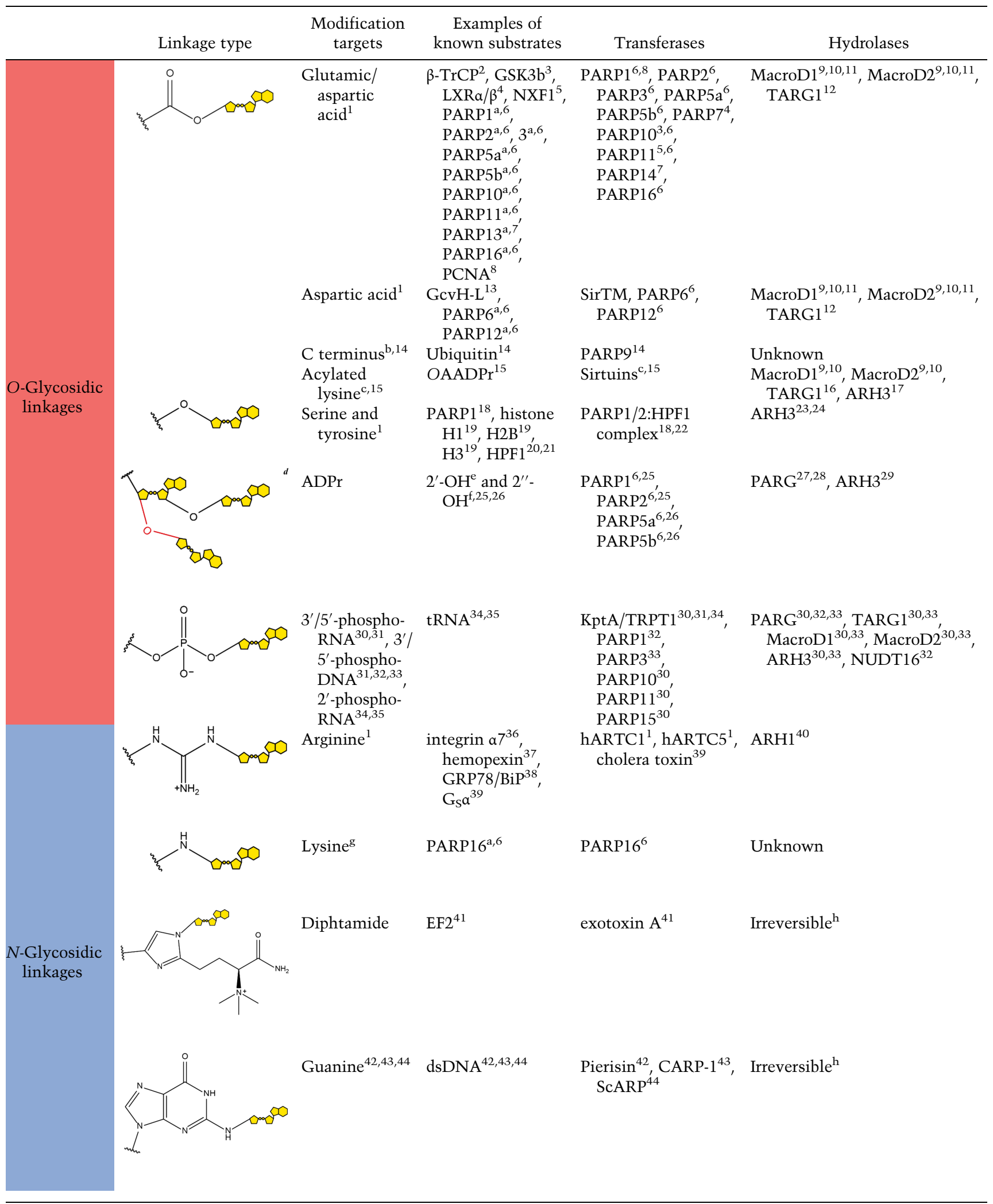


Table 1. Continued

\begin{tabular}{|c|c|c|c|c|c|}
\hline & Linkage type & $\begin{array}{l}\text { Modification } \\
\text { targets }\end{array}$ & $\begin{array}{c}\text { Examples of } \\
\text { known substrates }\end{array}$ & Transferases & Hydrolases \\
\hline $\begin{array}{l}S \text {-Glycosidic } \\
\text { linkage }\end{array}$ & & Cysteine $^{1}$ & $\operatorname{PARP}^{\mathrm{a}, 6}, 16^{\mathrm{a}, 6}$ & $\mathrm{PARP}^{6}{ }^{6}, \mathrm{PARP} 16^{6}$ & Unknown \\
\hline Unknown & & Thymidine ${ }^{45}$ & $\begin{array}{l}\text { ssDNA:TNTC } \\
\text { motif }^{45}\end{array}$ & $\operatorname{DarT}^{45}$ & $\operatorname{DarG}^{45}$ \\
\hline
\end{tabular}

${ }^{\mathrm{a}}$ Automodified in vitro.

${ }^{\mathrm{b}}$ Gly76 of ubiquitin.

${ }^{\mathrm{c}}$ The deacylation reaction catalyzed by sirtuins can be viewed as acylic acid transfer from lysine residues onto ADPr.

${ }^{\mathrm{d}}$ Branch point linkage highlighted in red.

'Forming linear $1^{\prime \prime} \rightarrow 2$ ' extensions

${ }^{\mathrm{f}}$ Forming branch points with $1^{\prime \prime} \rightarrow 2^{\prime \prime}$ linkage.

${ }^{\mathrm{g}} \mathrm{Cl}^{\prime \prime}$ linked lysine can undergo Amadori rearrangement leading to a ketoamine product (see Fig. 6A, below).

${ }^{\mathrm{h}}$ Irreversible has been suggested and so far no reversing activity has been described.

Table references: ${ }^{1}$ Crawford et al. 2018; ${ }^{2}$ Guo et al. 2019; ${ }^{3}$ Feijs et al. 2013; ${ }^{4}$ Bindesbøll et al. 2016; ${ }^{5}$ Carter-O'Connell et al. 2016; ${ }^{6}$ Vyas et al. 2014; ${ }^{7}$ Carter-O'Connell et al. 2018; ${ }^{8}$ Zhang et al. 2013; ${ }^{9}$ Chen et al. $2011 ;{ }^{10}$ Jankevicius et al. 2013; ${ }^{11}$ Rosenthal et al. 2013; ${ }^{12}$ Sharifi et al. 2013; ${ }^{13}$ Rack et al. 2015; ${ }^{14}$ Yang et al. 2017; ${ }^{15}$ Sauve and Youn 2012; ${ }^{16}$ Peterson et al. 2011; ${ }^{17}$ Ono et al. 2006; ${ }^{18}$ Bonfiglio et al. 2017; ${ }^{19}$ Leidecker et al. 2016; ${ }^{20}$ Leslie Pedrioli et al. 2018; ${ }^{21}$ Bartlett et al. $2018 ;{ }^{22}$ Palazzo et al. 2018; ${ }^{23}$ Fontana et al. 2017; ${ }^{24}$ Abplanalp et al. 2017; ${ }^{25} \mathrm{D}^{\prime}$ Amours et al. $1999 ;{ }^{26}$ Rippmann et al. $2002 ;{ }^{27}$ Brochu et al. 1994; ${ }^{28}$ Barkauskaite et al. $2013 ;{ }^{29}$ Oka et al. 2006; ${ }^{30}$ Munnur et al. 2019; ${ }^{31}$ Munir et al. 2018b; ${ }^{32}$ Talhaoui et al. 2016; ${ }^{33}$ Munnur and Ahel 2017; ${ }^{34}$ Munir et al. $2018 \mathrm{a} ;{ }^{35} \mathrm{Bane}$ rjee et al. 2019; ${ }^{36}$ Zolkiewska and Moss 1993; ${ }^{37}$ Leutert et al. $2018 ;{ }^{38}$ Fabrizio et al. $2015 ;{ }^{39}$ Vanden Broeck et al. $2007 ;{ }^{40}$ Moss et al. $1985 ;{ }^{41}$ Honjo et al. $1968 ;{ }^{42}$ Takamura-Enya et al. $2001 ;{ }^{43}$ Nakano et al. $2006 ;{ }^{44}$ Nakano et al. $2013 ;{ }^{45}$ Jankevicius et al. 2016.

TRPT1/KptA and several mammalian PARPs have been found to modify the termini of phosphorylated nucleic acids (Talhaoui et al. 2016; Munnur and Ahel 2017; Munir et al. 2018b; Munnur et al. 2019).

In addition to these intrinsic specificities, recent studies have highlighted that the target preference of some transferases can be altered depending on the cellular context. For example, PARP1 and 2 (PARP1/2) catalyze primarily the modification of acidic residues via ester-type $O$-glycosidic linkages in vitro. However, the main type of ADPribosylation produced by PARP1/2 in response to DNA damage is the modification of serine residues through an ether-type O-glycosidic linkage (Table 1; Leidecker et al. 2016; Fontana et al. 2017; Larsen et al. 2018; Palazzo et al. 2018). This discrepancy was reconciled by the discovery of the auxiliary histone PARylation factor 1 (HPF1), which interacts with PARP1/2 and induces the observed switch in activity (Gibbs-Seymour et al. 2016; Bonfiglio et al. 2017; Palazzo et al. 2018). Further evidence suggests that the PARP1/2:HPF1 interaction may also enable synthesis of tyrosine-linked ADP-ribosylation (Bartlett et al. 2018; Leslie Pedrioli et al. 2018).

Apart from mono(ADP-ribosyl)ation (MARylation), PARP1, PARP2, and PARP5a/b (tankyrase-1/2) were shown to synthesize linear ADP-ribose polymers, termed poly(ADP-ribosyl)ation (PARylation), with a ribose $\left(1^{\prime \prime} \rightarrow\right.$ 2')ribose-phosphate-phosphate backbone (Fig. 1; Table 1; D'Amours et al. 1999; Vyas et al. 2014). In addition, PARP1/2 can infrequently ( $<3 \mathrm{~mol} \%)$ introduce branch points with ribose $\left(1^{\prime \prime} \rightarrow 2^{\prime}\right)$ ribose $\left(1^{\prime \prime} \rightarrow 2^{\prime \prime}\right)$ ribose structures into the polymer (Alvarez-Gonzalez and Jacobson 1987; D'Amours et al. 1999; Chen et al. 2018). Together, this spectrum of different modification sites and types makes
ADP-ribosylation one of the most intricate and versatile PTMs.

\section{Beyond PTMs: ADP-ribosylation of nucleic acids}

Despite their evolutionary separation, TRPT1/KptA-type transferases are sometimes classified as the 18th PARP. KptA was first characterized in yeast as a tRNA 2'-phosphotransferase that removes the 2 -phosphate at the splice junction generated by fungal tRNA ligase through a twostep reaction: (1) The internal RNA 2'-phosphate reacts with $\mathrm{NAD}^{+}$to form an RNA-2'-phospho-ADP-ribosyl

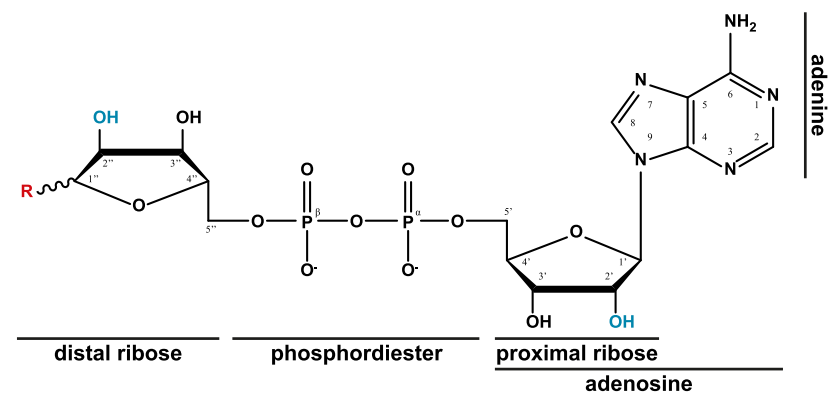

Figure 1. The chemical structure of ADP ribose, including atom and substructure labels, as used in this review. Throughout the ADP-ribosylation cycle different moieties $(\mathrm{R}, \mathrm{red})$ are attached to the anomeric carbon $\left(\mathrm{Cl}^{\prime \prime}\right)$; namely, the substrate $\beta-\mathrm{NAD}^{+}$(nicotinamide is linked trans relative to the $\left.2^{\prime \prime} \mathrm{OH}\right)$, the formed reaction products (linked cis $[\alpha]$ relative to the $2^{\prime \prime} \mathrm{OH}$ ) (Table 1 ), and $\operatorname{ADPr}\left(1^{\prime \prime} \mathrm{OH}\right.$; anomeric mixture in aqueous solution). Linkage sites of consecutive ADP-ribose moieties within PAR are highlighted in blue ([2'] linear linkage; $\left[2^{\prime \prime}\right]$ branch point linkage). 
RNA intermediate, and (2) transesterification of the ADPribose $2^{\prime \prime}-\mathrm{OH}$ to the $2^{\prime}$-phosphodiester generates $2^{\prime}-\mathrm{OH}$ RNA and ADP-ribose-1", $2^{\prime \prime}$-cyclic phosphate (Spinelli et al. 1999; Steiger et al. 2001, 2005; Munir et al. 2018a). Surprisingly, TRPT1/KptA is evolutionary conserved in Archaea and Animalia, whose tRNA exon ligation does not result in a 2 '-phosphate junction, as well as in bacterial species, which have no known intron-containing tRNAs and/or no known pathways to generate RNAs with internal 2'-phosphate modifications (Spinelli et al. 1998; Popow et al. 2012). These observations suggested that TRPT1/KptA might catalyze additional enzymatic reactions other than RNA 2'-phosphate removal; for example, TRPT1/KptA from Aeropyrum pernix and humans catalyze the $\mathrm{NAD}^{+}$-dependent ADP-ribosylation of either RNA or DNA 5'-monophosphate termini (Munir et al. 2018b; Munnur et al. 2019). Moreover, several PARPs are capable of ADP-ribosylating DNA or RNA ends in vitro. Among them; DNA repair PARPs (PARP1-3) can modify terminal phosphate moieties at DNA breaks with diverse specificity; i.e., PARP2 and PARP3 preferentially act on $5^{\prime}$-phosphates in nicked duplex DNA, whereas PARP1 modifies $3^{\prime}$ - and $5^{\prime}$-phosphates as well as the terminal $2^{\prime}-\mathrm{OH}$ groups in single-strand or double-strand DNA (Talhaoui et al. 2016; Munnur and Ahel 2017; Belousova et al. 2018; Zarkovic et al. 2018). Beyond DNA, the antiviral PARPs 10, 11, and 15 have been shown to ADP-ribosylate phosphorylated RNA termini (Munnur et al. 2019). Although the cellular functions of this modification have so far not been investigated, it is tempting to speculate that it is involved in DNA damage repair, transcript processing, and/or defence against exogenous RNAs; e.g., of viral origin.

A group of highly diverged ARTCs, the NAD ${ }^{+}$:monoADP-D-ribosyl-DNA(guanine- $\mathrm{N}^{2}$ )-ADP-D-ribosyltransferases, including pierisins (e.g., from Pierisin rapae), CARP-1 (e.g., from Meretrix lamarckii) and ScARP (e.g., from Streptomyces scabies), can directly modify guanine bases of dsDNA (Takamura-Enya et al. 2001; Nakano et al. 2006, 2013, 2015). While little is known about their physiological role, it was suggested that pierisin-1 is an important defence factor of cabbage butterflies against parasitization (Takahashi-Nakaguchi et al. 2013). Similarly, DarT, a bacterial PARP-like endotoxin, catalyzes the reversible transfer of ADP-ribose onto thymine bases of ssDNA, a process suggested to be involved in the response to adverse environmental conditions (Jankevicius et al. 2016).

\section{ADP-ribosylation reversal}

The chemical nature of the ADPr-protein linkage as well as the length and complexity of the modification can significantly affect the PTM's half-life, the order in which downstream events occur, as well as the enzymes needed to reverse it (Alvarez-Gonzalez and Althaus 1989; Brochu et al. 1994). The hydrolysis of ADP-ribosylation linkages is carried out by members of two evolutionary distinct protein families: the macrodomains and the (ADP-ribosyl)hydrolases (ARHs). Macrodomains are both "readers" and "erasers" of ADP-ribosylation and can be evolutionary subdivided into at least six phylogenetic classes. The hydrolytically active family members are associated with either the MacroD-type (MacroD1 and MacroD2 in humans), ALC1-like (human TARG1), or PARG-like class (human PARG) (Table 1; Rack et al. 2016). Of these enzymes, MacroD1, Macro2, and TARG1 break the O-glycosidic ester bond of modified aspartates, glutamates, and $O$ acetyl-ADPr (OAADPr), the reaction product of the $\mathrm{NAD}^{+}$-dependent sirtuin deacetylases, as well as phosphate ester at nucleic acid ends (Sauve and Youn 2012; Rack et al. 2016; Munnur et al. 2019|. PARG degrades polymers by hydrolysis of the ribose-ribose ether bond, but cannot act on the terminal protein-ribose bond (Slade et al. 2011). Three vertebrate ARH homologs were identified with ARH1 and ARH3 being confirmed hydrolases, whereas ARH2 is suspected to be catalytically inactive (Table 1; Moss et al. 1985; Oka et al. 2006; Ono et al. 2006; Smith et al. 2016; Rack et al. 2018). The available data indicate that ARH1 specifically reverses MARylation of arginine residues and appears to play a role in bacterial infections involving cholera exotoxins-like transferases (Moss et al. 1985, 1986; Kato et al. 2007). In contrast, ARH3 has a broad target spectrum including OAADPr, modified serine residues as well as PAR (Oka et al. 2006; Ono et al. 2006; Fontana et al. 2017; Bartlett et al. 2018). Both, ARH3 and PARG are recruited to DNA damage sites and are reported to play important parts in the DNA damage response (Mortusewicz et al. 2011; Palazzo et al. 2018; Wang et al. 2018). As for PARP1/2, this overlap in ARH3 and PARG localization and activity is yet another indication for redundancy in the ADP-ribosylation system, but may also indicate a regulatory aspect. In vitro and in vivo data suggest that PARG is the primary cellular PAR hydrolase (Alvarez-Gonzalez and Althaus 1989; Brochu et al. 1994; Fontana et al. 2017; Drown et al. 2018). However, the catalytic efficiency of PARG decreases for short polymers (less than four units) (Barkauskaite et al. 2013); hence, it is tempting to speculate whether these oligomers as well as the terminal serine linkage are the primary substrate for ARH3. This idea is supported by the fact that ARH3 knockout (KO) cells have a dramatically increased level of persistent MARylation marks, especially on histones, even in the absence of exogenous DNA damage (Fontana et al. 2017; Palazzo et al. 2018).

In addition to this complete removal of the ADP-ribosyl modification, several noncanonical mechanisms of processing have been proposed. Members of the Legionella pneumophila SidE effector proteins use a cascade of arginine-ADP-ribosylation on ubiquitin, phosphodiestercleavage, and transfer of the phosphor-ribosyl-ubiquitin onto an acceptor protein as a novel ubiquitination mechanism (Bhogaraju et al. 2016; Puvar et al. 2019). Similarly, it has been demonstrated in vitro that hydrolysis of the phosphodiester bond by NUDT16, ENPP1, or snake venom phosphodiesterases leaves phosphoribosyl-modified proteins (Matsubara et al. 1970; Palazzo et al. 2015, 2016). It remains an open question whether NUDT16 and ENPP1 can process ADP-ribosylated proteins also in vivo and what the associated downstream processing or 
functional consequences of the phosphoribosyl modification would be.

In recent years, attention in the community has increasingly shifted toward studying erasers of ADP-ribosylation: their molecular functions, physiological roles, and influence on human health and disease. Below, we discuss these new insights into ADP-ribosylation reversing enzymes and give an overview of the structural-functional features and biological roles.

\section{Hydrolases of the macrodomain family}

Macrodomains are evolutionarily conserved structural modules of $\sim 25 \mathrm{kDa}$ with a typical length of 150-210 amino acids. The core motif of all macrodomains consists of a three-layer $(\alpha / \beta / \alpha)$ sandwich architecture with a central six-stranded mixed $\beta$-sheet flanked by five $\alpha$ helices (Allen et al. 2003; Till and Ladurner 2009). Structurally it belongs in the leucine aminopeptidase (subunit E, domain 1) superfamily (CATH classification 3.40.220.10), which characteristically consist of nucleotide and nucleic acidbinding domains (Dawson et al. 2017). Macrodomains were shown to be binders of ADPr moieties as found in OAADPr, MAR-, and PARylated proteins (Karras et al. 2005). The ADPr moiety binds in a deep cleft located on the crest of the domain. Within the macrodomain family, three classes have catalytically active hydrolases as members (for review, see Rack et al. 2016).

\section{The PARG-like class}

PARGs take a special place among the macrodomains as they are the only known members to possess PAR-degrading activity (Feng and Koh 2013). In mammals, a single gene encodes alternative splice variants, which are believed to play a major role in its regulation, the subcellular distribution of de-PARylation activity as well as tissue specificity (Fig. 2; Meyer et al. 2003; Cortes et al. 2004; Meyer-Ficca et al. 2004; Cozzi et al. 2006; Niere et al. 2012). For example, PARG $_{111}$ (isoforms are designated by the molecular weight of the corresponding protein) is a primarily nuclear protein and responsible for the degradation of PARP1/2-derived PAR following genotoxic stress (Min et al. 2010), while PARG 102 and PARG PAg $_{92}$ show cytoplasmic and perinuclear localization and are thought to act on the large fraction of PAR residing in the perinuclear region (Winstall et al. 1999; Gagné et al. 2001). Furthermore, hydrolytic activity of the latter appears to be required for the regulation of PAR-induced cytoplasmic granules and protein aggregates (Grimaldi et al. 2019).

Dysfunctions in the hydrolysis of PAR chains induced by Parg inactivation are embryonically lethal in mice. Nevertheless, $\mathrm{Parg}^{-/-}$mouse trophoblast-derived stem cells are able to survive in the presence of chemical inhibitors of PARP1/2, suggesting that the accumulation of PAR chains, due to the absence of PARG activity, represents a cell death signal (Koh et al. 2004). Importantly, PARG depletion leads to hypersensitivity to genotoxic and replication stress and, consequently, it was proposed

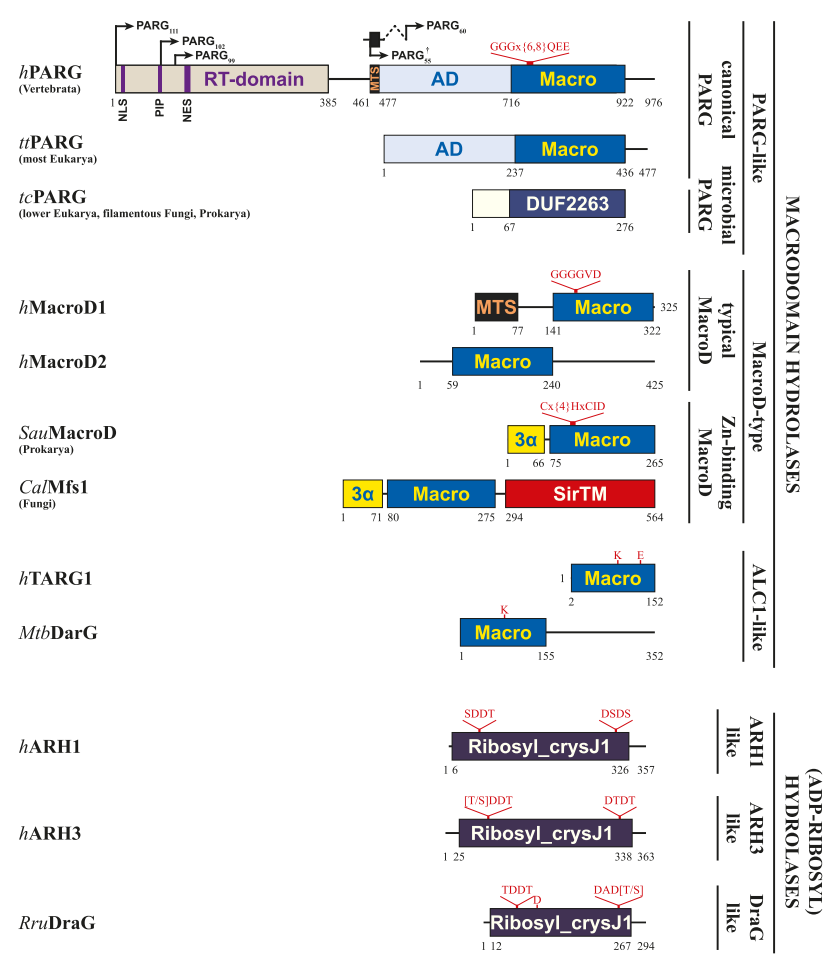

Figure 2. Domain structure of macrodomains and (ADP-ribosyl) hydrolases. The hydrolytic domains are Macro (macrodomain), DUF2263, (microbial PARG), and Ribosyl_crys)1 (ADP-ribosylation/Crystallin J1 fold), respectively. Subtype-specific sequence motifs are given above the first domain structure (red) of its type. Canonical PARGs contain an accessory domain (AD). In vertebrata, the $\mathrm{AD}$ contains a mitochondrial-targeting signal (MTS) and the N terminus is extended by a regulatory and targeting domain (RT domain), which holds the nuclear localization and export signal (NLS and NES, respectively) as well as a PCNA-interacting protein (PIP) box. Other domains: $3 \alpha$, 3- $\alpha$-helical bundle; SirTM, sirtuin of M class. Alternative splicing of the single PARG gene in humans is indicated above hPARG. Note that the PARG $_{60}$ transcript involves splicing of exons 1 and 4 as well as exclusion of exon 5 leading to an altered $\mathrm{N}$-terminal sequence, but including the MTS. The arrow indicates the position from which the primary sequence corresponds to the other splice variants. ( $t$ ) PARG $_{55}$ derives from the usage of an alternative start codon in the $\mathrm{PARG}_{60}$ transcript.

as a novel target for modern chemotherapeutic approaches (James et al. 2016; Palazzo and Ahel 2018; Pillay et al. 2019). In addition to its functions in DNA repair, PARG activity seems to be involved in the progression of replication forks and recovery from persistent replication stress (Illuzzi et al. 2014; Ray Chaudhuri et al. 2015). These observations are in agreement with the interaction of PARG with the replication helicase PCNA and its localization to replication foci during S-phase (Fig. 2; Mortusewicz et al. 2011; Kaufmann et al. 2017).

\section{Structure and function of PARG-like hydrolases}

Evolutionarily, the PARG-like class can be subdivided into the canonical PARGs, found primarily in higher 
organisms, and the microbial PARGs, often annotated as DUF2263 (Slade et al. 2011). While the latter resemble largely classical macrodomains, canonical PARGs occur together with a mainly $\alpha$-helical accessory domain that extends the core motif into a typically 10 -stranded $\beta$-sheet (Figs. 2, 3A). The ADPr-binding cleft, as in other macrodomains, is part of the canonical core fold and the physiological role of the accessory domain, beyond its effects on overall protein stability, remains elusive. Within the binding cleft, the adenine moiety of the ADPr lies parallel to the protein surface and is shielded from the aqueous environment by $\pi-\pi$-stacking with a conserved phenylalanine (Phe902 in humans) (Fig. 4). Adenine binding is further stabilized by extensive protein and water-mediated contacts with the amino group on C6, as well as with the ring nitrogens N1 and N7 (Figs. 1,4). These contacts convey ligand specificity as their disruption by an exchange of adenine by hypoxanthine, which substitutes the C6 amino group with a keto group, has been shown to severely diminish ADPr binding to PARG (Drown et al. 2018; Rack et al. 2018). In canonical PARGs, ligand binding is further stabilized by a highly conserved tyrosine (Tyr795 in humans) that coordinates $\mathrm{O}^{\prime}$ and edge stacks with the adenosine moiety (Kim et al. 2012; Tucker et al. 2012; Lambrecht et al. 2015). Recently, these highly specific properties of the adenine-binding pocket were utilized for the development of a series of high-potency, competitive inhibitors (Waszkowycz et al. 2018). Further along the ligand, the diphosphate-binding loop coordinates both the diphosphate and distal ribose and participates in forcing a strained conformation in this part of the molecule. The strained conformation is achieved via a hydrophobic patch $(\mathrm{G}[\mathrm{A}, \mathrm{V}][\mathrm{F}, \mathrm{Y}]$ motif) within the loop, which bends the distal ribose toward the catalytic loop and positions $\mathrm{Cl}^{\prime \prime}$ and $\mathrm{Ol}^{\prime \prime}$ in relative proximity to $\mathrm{P}^{\alpha}$. The conformation is further stabilized by a structural water molecule bridging the ribose and phosphate group (Fig. 1B). In canonical PARGs, a highly conserved asparagine (aspartate in microbial PARGs) precedes the catalytic GGGx $\{6,8\} \mathrm{QEE}$ motif and interacts with the $3^{\prime \prime} \mathrm{OH}$ group.
Binding of the PAR substrate was suggested to increase the $\mathrm{pK}_{\mathrm{a}}$ of the catalytic glutamate (Glu756 in humans), which facilitates its protonation and allows it to act as the general base in the initial step of the reaction (Fig. 1C; Slade et al. 2011; Dunstan et al. 2012; Kim et al. 2012; Tucker et al. 2012; Barkauskaite et al. 2013). The carboxyl hydrogen of Glu756 is transferred to the PARleaving group, while an oxocarbenium intermediate is formed on the bound distal ribose. The deprotonated Glu756 then assists in the activation of a water molecule, which reacts with the oxocarbenium intermediate and forms the ADPr product. It should be noted that due to the placement of Glu756 relative to the distal ribose, it is as yet unclear from which site the ADPr forming water attacks the ribose, and hence whether the $\alpha$ or $\beta$ product is formed (Kim et al. 2012). Interestingly, in microbial PARGs the proximal ribose is coordinated and shielded from the aqueous environment (Slade et al. 2011), which makes this subclass strict exohydrolases. In contrast, canonical PARGs are only primarily exo-hydrolases and the more open positioning of the proximal ribose within the binding cleft allows an endo-binding mode and congruously weak endo activity has been observed in vitro (Barkauskaite et al. 2013; Lambrecht et al. 2015). However, it remains to be elucidated whether this activity is of physiological relevance.

\section{The MacroD-type class}

Members of the MacroD-type hydrolases are widely distributed among all domains of life and several viruses (Chen et al. 2011; Rack et al. 2015, 2016; Fehr et al. 2018). In humans, the MacroD-type class has two members with highly similar catalytic domains, MacroD1 (also known as Leukaemia-Related Protein 16 [LRP16]) and MacroD2. Both enzymes are mono(ADP-ribosyl) hydrolases and active in vitro against protein substrates modified on acidic amino acids (Barkauskaite et al. 2013; Jankevicius et al. 2013; Rosenthal et al. 2013;
A
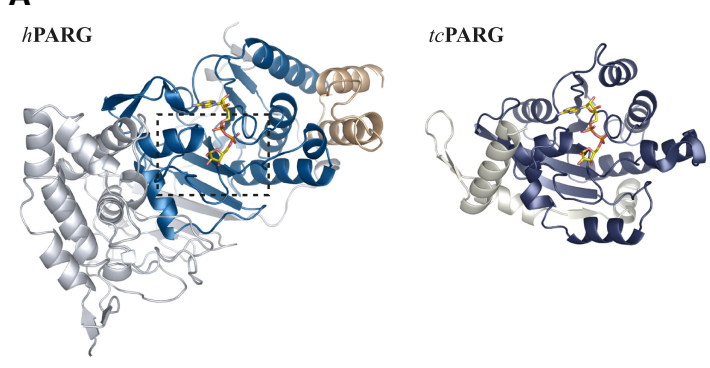

B

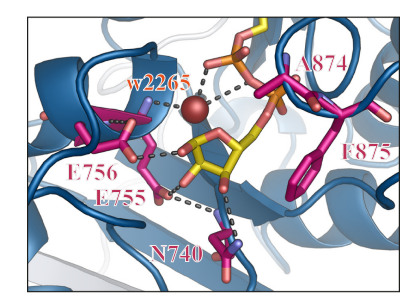

C

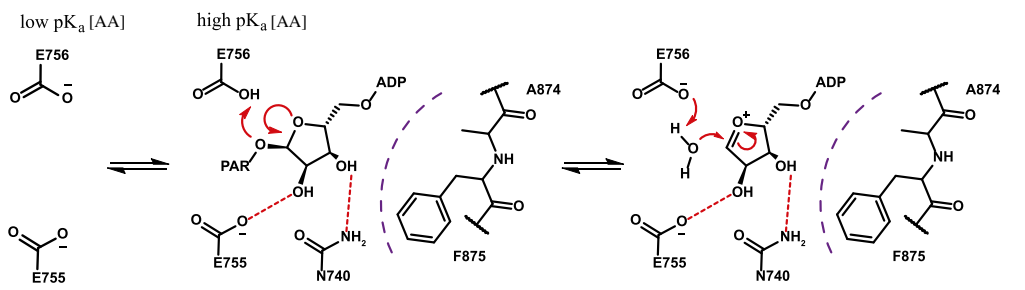

Figure 3. PAR degradation by PARG-like hydrolases. (A) Ribbon representation of the catalytic domains of canonical PARGs (depicted $h$ PARG; PDB 4B1H) and microbial PARGs (depicted tcPARG; PDB 3SIG) in complex with ADPr. (B) Close up of the active site of hPARG. (Yellow) ADPr; (magenta) residues involved in ligand orientation and catalysis; (red) structural water (w2265); (dashed lines) selected polar interaction. (C) Potential reaction mechanism for PARG-like enzymes. Residue numbering is in accordance with human $\mathrm{PARG}_{111}$. 

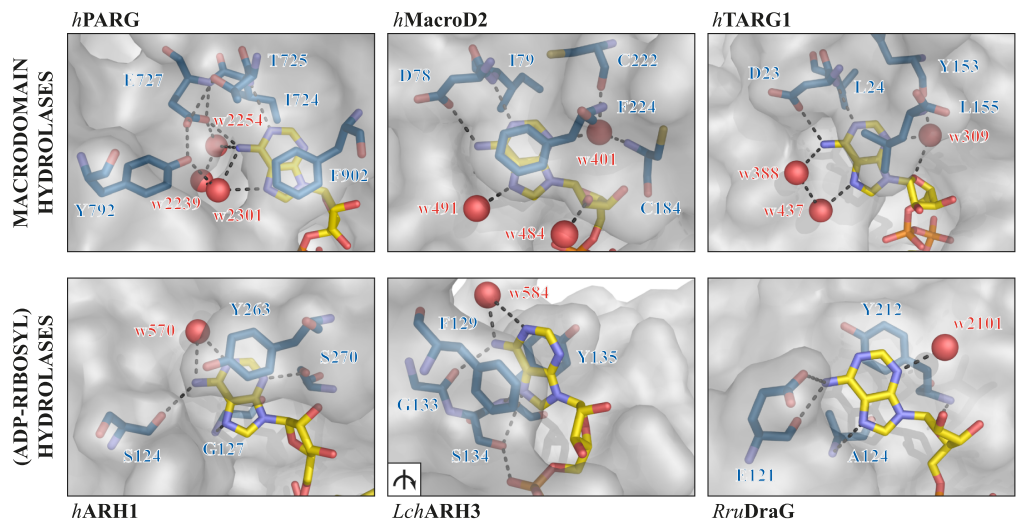

Figure 4. Comparison of adenine coordination across macrodomains and (ADP-ribosyl)hydrolases. Surface-liquorice representation of adenine coordination. The adenine base lies against the protein surface in most hydrolases with the exception of ARH3 in which it holds by $\pi-\pi$ stacking perpendicular to the protein surface (view rotated [arrow] by $\sim 60^{\circ}$ relative to the closeups). (Yellow) ADPr; (blue) coordinating residues; (red) waters; (dashed lines) selected polar contacts.
Rack et al. 2016). Furthermore, other studies suggest that they can also hydrolyze OAADPr as well as (ADP-ribosyl) ated nucleic acids (Chen et al. 2011; Munnur and Ahel 2017; Agnew et al. 2018; Munnur et al. 2019). MacroD1 localizes largely to the mitochondrial matrix (Agnew et al. 2018), whereas MacroD2 distributes in the cytosol and nucleus (Jankevicius et al. 2013; Golia et al. 2017). The physiological substrates and cellular functions of both MacroD1 and MacroD2 remain largely elusive. However, links to the DNA damage response and signal transduction have been reported.

\section{MacroD1 and MacroD2}

Aberrant MacroD1 expression and gene fusions contribute to tumour pathology; e.g., in leukaemia, breast, gastric, liver, lung, and colorectal cancer (Imagama et al. 2007; Shao et al. 2015; Sakthianandeswaren et al. 2018). Several lines of evidence indicate that MacroD1 is involved in several important signaling pathways: In breast cancer-derived MCF-7 cells, MacroD1 expression is induced by estrogenic hormones in an estrogen receptor alpha $(\mathrm{ER} \alpha)$-dependent manner and subsequently acts as a cofactor for ERa and the androgen receptor (Han et al. 2007; Yang et al. 2009). In response to DNA double-strand breaks, MacroD1 is activated and enriched in the cytosol, which stimulates prosurvival and antiapoptotic functions of the dimeric (p65/p50) transcription factor NF- $\mathrm{kB}$ (Li et al. 2017). MacroD1 stimulates the activity of NF-kB through the interaction with p65 and UXT, a transcription factor coregulator (Wu et al. 2011, 2015). In hepatocytes, MacroD1 interacts and regulates liver $X$ receptors $\alpha$ and $\beta$ when these are MARylated by PARP7 (Bindesbøll et al. 2016). Furthermore, MacroD1 was also proposed to act as a negative regulator of the insulin signaling pathway through the down-regulation of the insulin receptor substrate protein-1 (IRS-1) (Zang et al. 2013).

The MacroD2 gene locus is a hot spot for mutations and chromosome rearrangements that have been associated with several human disorders, such as autism diseases, schizophrenia, and several tumors (Anney et al. 2010; Mohseni et al. 2014; Fujimoto et al. 2016; Autism Spectrum Disorders Working Group of The Psychiatric Genomics Consortium 2017). These mostly pathoneurological phenotypes of the MacroD2 gene are associated with its loss of function, thus suggesting a physiological role in the central nervous system. This correlates with robust neuronal expression of MacroD2 during brain development (Ito et al. 2018).

Alterations of MacroD2 functions in the DNA damage response and signal transduction may also be linked to tumor formation and/or progression. Indeed, MacroD2 is phosphorylated by ATM in response to DNA doublestrand breaks, as well as being involved in reversing the ADP-ribosylation of GSK3 $\beta$, a key kinase involved in the WNT-mediated signal transduction pathway (Feijs et al. 2013; Golia et al. 2017).

Despite the phenotypic and clinical associations, as well as the in vitro studies discussed above, the precise physiological roles and detailed molecular functions of both MacroD1 and MacroD2 remain poorly understood. For example, the presence of several hydrolases, including MacroD1, within the mitochondrial matrix (Fig. 2; Niere et al. 2008, 2012; Agnew et al. 2018), together with unbiased mass spectrometric evidence for ADP-ribosyl-modified proteins within this compartment (Hendriks et al. 2019) raises the question of whether ADP-ribosylation signaling has a regulatory function in mitochondria.

\section{Viral and microbial MacroDs}

Beyond the human MacroD1 and MacroD2 proteins, viruses and bacteria encode MacroD-type hydrolases, too. MacroD-type macrodomains are encoded by a set of positive-strand RNA viruses, such as Coronaviridae (including severe acute respiratory syndrome [SARS-CoV] and Middle East respiratory-related coronavirus [MERSCoV]), Togaviridae, and Hepeviridae, which all show (ADP-ribosyl)hydrolase activity against MARylated aspartate and glutamate-modified substrates (Fehr et al. 2016, 2018; Li et al. 2016; Rack et al. 2016; Eckei et al. 2017; McPherson et al. 2017; Lei et al. 2018; Leung et al. 2018; Grunewald et al. 2019). Although physiological substrates of viral MacroD-type hydrolases are not clear, they are known to be important for viral replication most likely due to their ability to counteract the host immune response by working against antiviral PARPs (PARP7, PARP9, PARP10, and PARP12-PARP15) 
(Atasheva et al. 2014; Li et al. 2016; McPherson et al. 2017; Fehr et al. 2018; Leung et al. 2018; Grunewald et al. 2019). This was recently corroborated by the observation that VEEV and SARS macrodomain-containing proteins can efficiently reverse PARP10-derived RNA ADP-ribosylation in vitro (Munnur et al. 2019). Noteworthy, this aspect of viral-induced stress may create evolutionary pressure and thus contribute to the rapid positive selection observed in antiviral PARPs (Daugherty et al. 2014; Gossmann and Ziegler 2014). Expression of PARP9, PARP1214 is potently stimulated by interferon type I in response to viral infection (Juszczynski et al. 2006; Schoggins et al. 2011; Welsby et al. 2014), thus suggesting that ADP-ribosylation signaling is required for an efficient viral response. Indeed, overexpression of several PARP genes has been shown to inhibit replication of viruses (Atasheva et al. 2012, 2014). This role is partially realized through the formation of stress granules, transient cytoplasmic membraneless structures that include untranslated mRNA, specific proteins, as well as PAR, and which exhibit antiviral function among others (McInerney et al. 2005; Leung et al. 2011; Grimaldi et al. 2019). It was shown that the alphaviral macrodomain-containing nonstructural protein 3 (nsP3) interferes with the formation of stress granules and, consequently, prevents their inhibitory effect on viral replication (McInerney et al. 2005; Abraham et al. 2018). Together, these findings lead to the suggestion that targeting of viral macrodomains is a promising antiviral strategy. The hypothesis gained support recently by the development of dihydrorugosaflavonoid derivatives as inhibitors of the nsP3 macrodomain and the demonstration that these compounds are effective in reducing viral RNA levels in the infected cells (Puranik et al. 2019).

MacroD-type hydrolases are also widely spread among microorganisms, but their physiological roles have so far been understudied. However, evidence from the few studied examples suggests that these enzymes are part of the cellular stress response (Kim et al. 2008; Rack et al. 2015). For example, cold stress leads to the activation of the macrodomain YmdB in Escherichia coli. Subsequently, YmdB interacts with the ribonuclease RNase III and acts as a negative regulator of its cleavage activity
(Kim et al. 2008; Paudyal et al. 2015). Furthermore, YmdB was suggested as a regulator of gene expression both through RNase III regulation as well as in an RNase III-independent manner, thereby influencing biofilm formation and antimicrobial resistance (Kim et al. 2013, 2017). While it was shown that YmdB is catalytically active (Chen et al. 2011; Zhang et al. 2015b), the role of this activity in vivo remains elusive. A second example of the studied microbial MacroD-type hydrolases are macrodomains associated with mono(ADP-ribosyl)transferases of the class M sirtuins (SirTMs) type that are found in bacteria (e.g., Clostridium, Treponema, and Lactobacillus species) and fungi (including Aspergillus, Candida, and Fusarium) (Chen et al. 2011; Rack et al. 2015). Extended operons containing a lipoyl-carrier protein (GcvH-L), a lipoyltransferase (LplA2), and the macrodomain-SirTM module are found almost exclusively in pathogenic bacteria, including Staphylococcus aureus and Streptococcus pyogenes. In this system, GcvH-L can be lipoylated by LplA2 and subsequently ADP-ribosylated by SirTM. The latter modification is reversible by the macrodomain. Interestingly, while the activity of the macrodomain is not dependent on the lipoylation, in vitro binding experiments indicate that the macrodomain interacts with GcvH-L in a lipoylation-dependent manner (Rack et al. 2015). SirTM operons in bacteria and fungi are induced by oxidative stress and it has been proposed that the lipoyl moiety acts as a reactive oxygen species (ROS) scavenger, while the ADP-ribosylation regulates its participation in the redox defence (Rack et al. 2015).

\section{Structure and function of MacroD-type hydrolases}

Members of the MacroD-type class partially resemble PARG proteins with respect to their ADPr-binding features (Figs. 4, 5A,B; Barkauskaite et al. 2013). However, there are some key differences in the active site that result in very distinct catalytic mechanisms. The polymer substrate of PARG contains defined ether O-glycosidic bonds, whereas the linkage to acidic residues and OAADPr, the preferred substrates of MacroD-type enzymes, are ester linkages. One important difference is that these esters undergo spontaneous transesterification; thus, glutamyl/
A

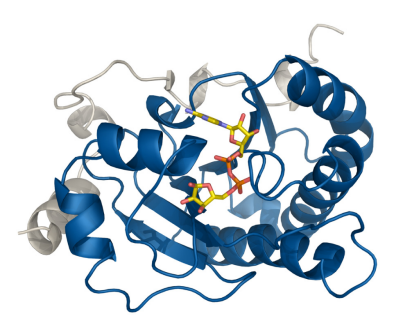

B

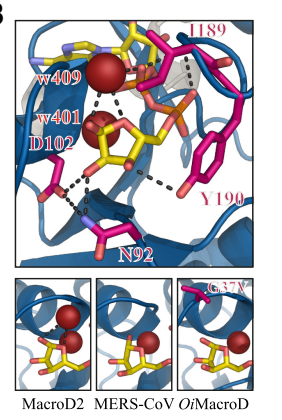

C

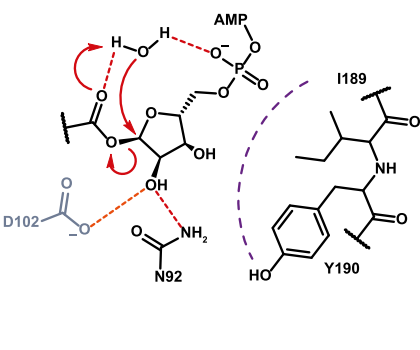

Figure 5. MacroD-type hydrolases. (A) Ribbon representation of hMacroD2 (PDB 4IQY) as typical representative of the MacroD-type class. (Blue) Macrodomain; (white) N-terminal extension; (yellow) ADPr. (B) The top panel shows closeup of the active site of hMacroD2. Color scheme as in A. (Magenta) Residues involved in ligand orientation and catalysis; (red) structural (w401) and catalytic water (w409); (dashed lines) selected polar interaction. The bottom panels show the replacement of the catalytic water from the active site in the hMacroD2: $\alpha$-ADPr complex

(PDB 4IQY), in the MERS-CoV macrodomain, due to cocrystallization with reaction product $\beta$-ADPr (PDB 5HOL), and in OiMacroD, due to p.G37V mutation (PDB 5LAU). (C) Potential reaction mechanism for MacroD-type enzymes. Residue numbering in accordance with $h$ MacroD2. Note: Asp102 is part of the proposed His/Asp dyad and is not present in all MacroD-type hydrolases. 
aspartyl of protein-linked ADPr or the acetyl moiety in OAADPr migrate to the $2^{\prime \prime}$ and $3^{\prime \prime}$ position and equilibrate between the three sites in a $\mathrm{pH}$-dependent manner (Kasamatsu et al. 2011; Kistemaker et al. 2016). Jankevicius et al. (2013) showed experimentally and in simulations that MacroD2 cleaves ADPr from the 1" position (Jankevicius et al. 2013). This can be attributed to the interaction between the carbonyl group and the conserved glycine within the catalytic loop, as well as shielding of the 2 "OH-group from the environment by a conserved asparagine (Asn92 in human MacroD2) in a fashion similar to PARG (Fig. 5B). Within the catalytic loop, the consecutive, catalytic glutamate residues are absent. Initial studies of human MacroD1 and MacroD2 identified a histidine and aspartate motif on helix a6 (MacroD2) coordinating the $2^{\prime \prime} \mathrm{OH}$, which were thought to constitute a catalytic dyad (Rosenthal et al. 2013). However, a recent study demonstrated catalytic activity of viral MacroD homologs that lack the key aspartate residue (Li et al. 2016). Taken together, these studies suggest a substrate-assisted reaction mechanism. It was proposed that $\mathrm{P}^{\alpha}$ could act as a general base for activation of the structural water molecule, which would attack the $\mathrm{Cl}^{\prime \prime}$ position and hydrolyze the ADPr linkage. However, this mechanism was disputed as the low $\mathrm{pK}_{\mathrm{a}}$ of the phosphate group ( 2) would disfavor this reaction (Barkauskaite et al. 2013, 2015). Recent structural studies on Oceanobacillus iheyensis MacroD (OiMacroD) identified a well-defined water molecule above the structural water that interacts with a second glycine in the catalytic loop (Figs. 2, 5B; Zapata-Pérez et al. 2017). Displacement of the water by a Gly $>$ Val mutation reduced the catalytic efficiency of OiMacroD fourfold without affecting protein stability or ADPr binding (Fig. 5B; Zapata-Pérez et al. 2017). The crystal structures of the SARS- and MERS-CoV macrodomains in complex with $\beta$-ADPr reveal occupation of the water binding site by the $\beta-1^{\prime \prime} \mathrm{OH}$ moiety, while the structural water remains bound in the same position (Fig. 5B; Egloff et al. 2006; Lei et al. 2018), thus suggesting that this newly described water is indeed the catalytic one. Furthermore, this arrangement makes it possible to transfer the proton from the water molecule onto the leaving group or the aqueous environment. A possible, substrate-assisted $S_{N} 2$ reaction is depicted in Figure 5C, but further studies are needed to elucidate the exact nature of the transition state, mechanism, and the differences between enzymes in which the His/ Asp dyad is present or absent, respectively. Comparison of MacroDs with available PARG structures revealed that the isostructural position of the catalytic MacroD glycine is not conserved but instead occupied by small aliphatic residues including alanine (tcPARG) or valine (hPARG) (Slade et al. 2011; Kim et al. 2012; Tucker et al. 2012). Consistently, no water isostructural to the proposed catalytic one can be observed in PARGs. Whether this exchange contributes to the inability of PARG to hydrolyze the terminal ADPr moiety from proteins remains, however, an open question.

Interestingly, a diverse subclass of MacroD enzymes, which are found associated with SirTMs in bacteria and fungi (Fig. 2), contain an amino acid exchange in the cata- lytic loop. Instead of the typical glycine-rich stretch going into helix a6 (MacroD2), these macrodomains have an extended catalytic loop containing a zinc-binding motif (Fig. 2; Appel et al. 2016). Positioning of the $\mathrm{Zn}^{2+}$ as part of the active site suggests a catalytic function of the ion and hence a diverged mechanism in comparison with the other members of this class.

\section{The ALC1-like class}

Defined by a similarity to the macrodomain of the chromatin remodeler ALC1 (Ahel et al. 2009; Gottschalk et al. 2009), the ALC1-like class contains both MARylation "readers" and "erasers." ALC1 class macrodomain proteins can be readily found in Animalia and scattered examples can be also identified amongst bacterial species (Perina et al. 2014).

\section{TARG1}

TARG1 (also known as OARD1 and C6orf130) is the only hydrolytically active member of the ALC1-like class in Animalia. It was shown to interact with PARP1 and to possess hydrolytic activity against $O$-acyl-ADPr esters, ADPr-phosphoresters at nucleic acid termini, MARylated proteins, as well as the ability to release whole polymers from the target protein (Peterson et al. 2011; Rosenthal et al. 2013; Sharifi et al. 2013; Munnur and Ahel 2017; Munnur et al. 2019). TARG1 is found in the nucleus and cytoplasm (Sharifi et al. 2013). In particular, TARG1 has been observed to localize at the transcriptionally active nucleoli and binds strongly to ribosomes and proteins associated with rRNA processing and ribosomal assembly factors. In response to DNA damage, TARG1 relocalizes to the nucleoplasm, where it may contribute to reverse protein ADP-ribosylation (Bütepage et al. 2018).

A homozygous TARG1 gene mutation was described in a family with 11 individuals affected by a severe and progressive neurodegeneration and seizure disorder without dysmorphic features. In detail, a premature stop codon within the exon 4 of TARG1 locus results in the formation of a truncated and nonfunctional TARG1 protein (Sharifi et al. 2013). In addition, a genome-wide association study revealed that the TARG1 gene could be associated with the loss of insulin sensitivity, a key factor contributing to metabolic disease. However, a functional link between TARG1 and the cellular insulin response has at yet not been established (Timmons et al. 2018).

\section{$\operatorname{DarG}$}

DarG is a member of the ALC1-like macrodomains found strictly as a two-component toxin-antitoxin operon in a variety of bacteria, including pathogens like Mycobacterium tuberculosis, enteropathogenic E. coli, and Pseudomonas aeruginosa, as well as several hyperthermophiles such as Thermus aquaticus (Sberro et al. 2013; Jankevicius et al. 2016). The toxin DarT, a Bc4486-like member 
of the PARP family (de Souza and Aravind 2012; Aravind et al. 2015), modifies ssDNA at thymine bases in a sequence-specific manner (Jankevicius et al. 2016). The formation of the (ADP-ribosyl)-DNA adduct is reversed via the action of the antitoxin DarG, which shares some functional features with TARG1 (Jankevicius et al. 2016). As such, DarTG represents the first characterized system for the reversible ADP-ribosylation of nucleic acids. While the exact physiological role of DarTG is unclear, it was shown that the toxin blocks DNA replication, and it has been speculated that the host bacteria may exploit this system in order to induce a persistence state to survive adverse environmental conditions including exposure to antibiotics (Jankevicius et al. 2016). If true, resuming growth would require DarG antitoxin activity, which would be in line with $M$. tuberculosis transposon mutagenesis studies indicating that DarG is an essential gene (Sassetti et al. 2003; Griffin et al. 2011). Taken together, the inhibition of DarG may present a new and promising therapeutic strategy to combat bacterial infections (Jankevicius et al. 2016).

\section{Structure and function of ALC1-like hydrolases}

In their overall structure, ALC1-like macrodomains are minimal without $\mathrm{C}$ - or $\mathrm{N}$-terminal extensions and only five $a$-helices (Fig. 2). The most considerable divergence to other macrodomain hydrolases is, however, their catalytic mechanism. Crystal structures of the TARG1:ADPr complex showed that in crystallo Lys 84 of TARG1 reacts with the distal ribose $\mathrm{Cl}^{\prime \prime}$ forming an open ring Amadori product (Fig. 6A,B; Sharifi et al. 2013). Further functional analysis of this residue revealed that it is together with Glu125 part of a catalytic dyad. Interestingly, mutation of Glu125 leads in vitro to the formation of a covalent reaction intermediate, indicating that the hydrolytic mechanism also proceeds through a covalent intermediate, which is resolved by Glu125 (Sharifi et al. 2013). Therefore, the authors suggested a reaction mechanism resembling that of 8-oxoguanine DNA glycosylase (OGG1) (Bruner et al. 2000). Such a mechanism would involve deprotonation of Lys 84 by Glu125 and an attack of the nitrogen onto the anomeric carbon with liberation of the modified glutamate/aspartate (Fig. 6B,C). Subsequently, the ribose of the resulting $\mathrm{N}$-gloycosidic intermediate opens up to form a Schiff base, which is susceptible to a nucleophilic water attack. This step leads to the formation of a ring-opened ADPr and enables regeneration of the catalytic lysine. While the mechanism explains neatly the observations and fits well with similar mechanism in other systems, two problems remain: First, the positioning of ADP-HPD and ADPr in the available structures resembles the binding mode of ADPr in MacroD-type and PARG-like macrodomains, and in this binding position the anomeric carbon is not available for the initial attack by the catalytic lysine residue. Second, the spontaneous transesterification of the substrate makes it possible that the hydrolysis could occur from the $2^{\prime \prime}$ or $3^{\prime \prime}$ position, and so far no experimental evidence is available to determine from which position the modification is cleaved.
In order to reconcile the positioning of the ribose within the active site, it was suggested that binding of the substrate is directed by the TARG1 diphosphate-binding loop, which would result in an alternative ribose conformation permissive for cleavage (Sharifi et al. 2013). Support for this comes from the DarG antitoxin structure in which a positive surface patch, presumably the ssDNAbinding site, runs perpendicular to the ADPr binding pocket (Fig. 6D; Jankevicius et al. 2016). This allows for the speculation that the distal ribose is orientated toward the catalytic residue. Whether such a reorientation occurs for small substrates such as OAADPr and whether hydrolysis indeed occurs from the $\mathrm{Cl}^{\prime \prime}$ position remains, however, a subject for future studies. It is also of note that DarG does not contain the catalytic Lys/Glu dyad and only the lysine residue remains conserved between the two enzymes (Jankevicius et al. 2016). Absence of both residues was noted in SCO6735, an ALC1-like hydrolase from Streptomyces coelicolor involved in antibiotic production (Lalić et al. 2016). This further indicates a major mechanistic diversification within the ALC1-like class. Taken together, important insights into this class of hydrolases have been achieved in recent years, but important questions remain: What are the mechanistic similarities and differences between TARG1, DarG, and SCO6735? Is this diversification within the ALC1-like class associated with a physiological function or necessity?

\section{The (ADP-ribosyl)hydrolase family}

The ARH family is an evolutionary highly conserved structural module adopting a mainly a-orthogonal bundle architecture with a typical domain length of 290-360 residues. The first family member was identified as an activating factor, now termed DraG, which reverses the arginine-ADP-ribosylation-inhibiting dinitrogenase reductase (Fe-protein) in Rhodospirillium rubum (Ludden and Burris 1976). An enzyme with the same activity and comparable properties, now known as ARH1, was later identified in animal cells (Moss et al. 1985).

\section{ARH1}

ARH1 is a cytoplasmic protein, which is ubiquitously expressed in human and mouse tissues (Moss et al. 1992). Its primary activity is the hydrolysis of the $N$-glycosidic arginine-ADPr bond and has negligible activity against PAR and OAADPR (Oka et al. 2006; Ono et al. 2006; Mashimo et al. 2014; Rack et al. 2018). Deficiency of Arh1 in mouse embryonic fibroblasts (MEFs) and tissues dramatically impairs the ability to hydrolyse endogenously produced arginine-modified substrates (Kato et al. 2007), suggesting that ARH1 is the main cytoplasmic enzyme carrying out this reaction. Although the physiological role of ARH1 is not well understood, phenotypic observation on $A r h 1^{-/-}$mice and derived Arh1-deficient MEFs suggest a leading role of ARH1 in intracellular signal transduction and cell cycle regulation. Indeed, depletion of Arh1 in MEFs led to an abnormal proliferation rate characterized 
A

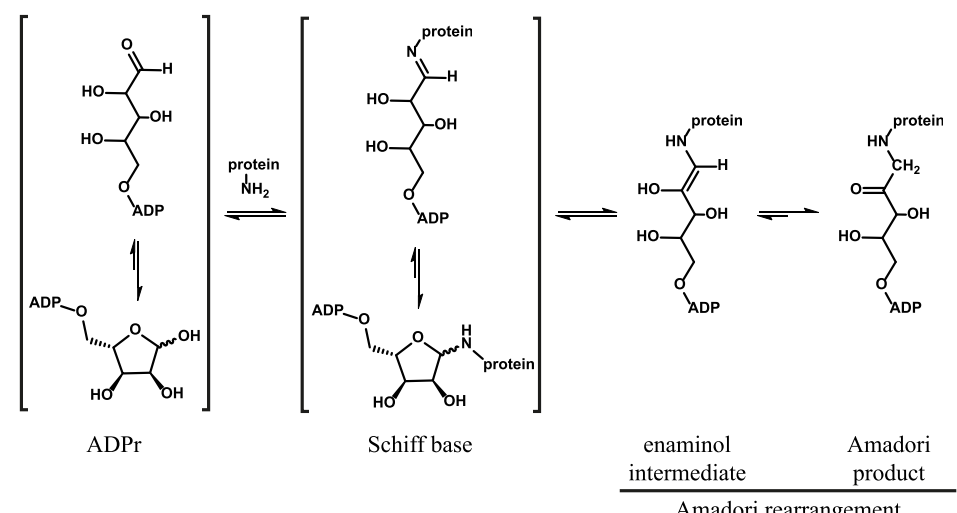

B
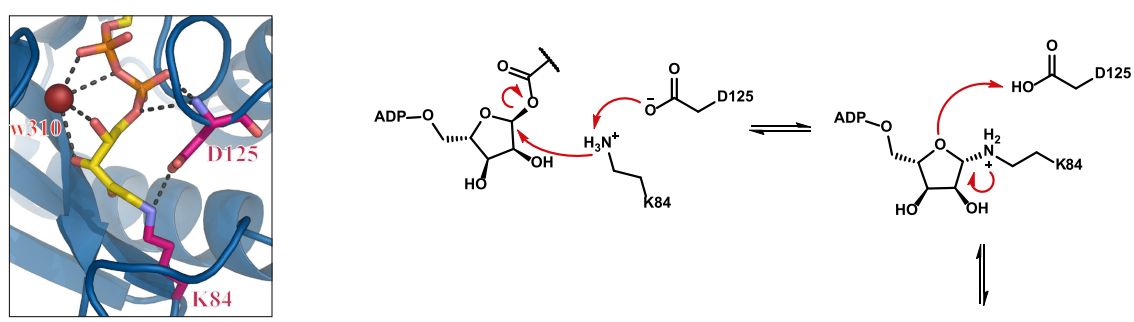

C
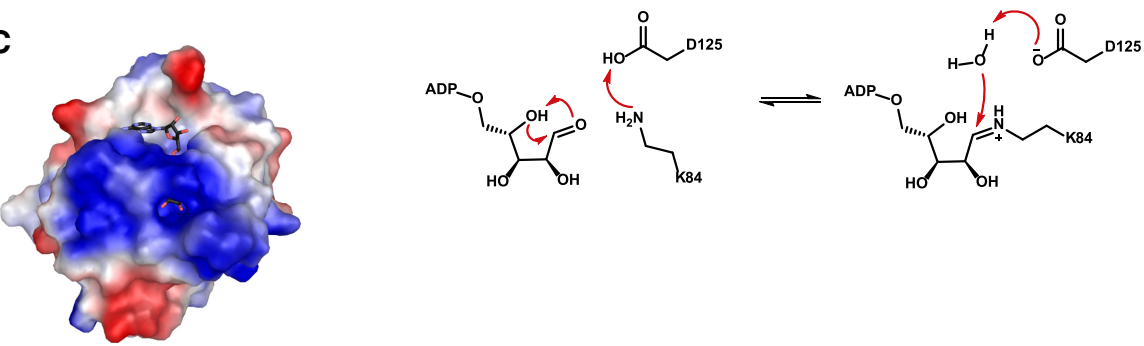

Figure 6. ALC1-like hydrolases. $(A)$ Reaction mechanism for the nonenzymatic formation of a Schiff base and the Amadori rearrangement. (B) Closeup of the active site of $h$ TARG1 in complex with the Amadori product of ADPr (yellow) and Lys84. (Magenta) Catalytic residues; (red) structural water (w310); (dashed lines) selected polar interaction. (C) Proposed reaction mechanism for TARG1 and related ALC1-like hydrolases. Residue numbering in accordance with hTARG1. (D) Electrostatic surface map of T. aquaticus DarG. (Red) Negative surface charge; (blue) positive surface charge; (white) neutral surface charge. Note that the prominent positively charged area, which runs perpendicular to the active site, was suggested as the DNA-binding surface. The cocrystallized ADPr is depicted in CPK coloring.

by a shortened G1 phase and rapid cell growth compared with wild-type MEFs (Kato et al. 2011). Consequently, it was observed that $A r h 1^{-/-}$and $A r h 1^{+/-}$mice have an increased risk of developing several types of tumors, including carcinoma, sarcoma, and lymphoma (Kato et al. 2011). Notably, estrogens play a key role in tumourigenesis observed in $\mathrm{Arh1} 1^{-1-}$ mice and MEFs, thus showing a significant gender-specific phenotype (Shim et al. 2013). The involvement of ARH1 in cancer progression is confirmed by the observation of frequent human somatic mutations in the ARH1 gene in lung, breast, and colon cancers (Kato et al. 2015). Some of these mutations directly impact the catalytic activity; e.g., the p.D56N missense mutation affects $\mathrm{Mg}^{2+}$ coordination and inactivates ARH1 (Kato et al. 2015; Rack et al. 2018).

In addition, ARH1 plays a role in the protection from Vibrio cholera infections (Kato et al. 2007; Watanabe et al. 2018). Cholera toxin, which is secreted during infection, inhibits the GTPase activity of the a subunit of the stimulatory guanine nucleotide-binding $\left(\mathrm{G}_{\mathrm{S}} \alpha\right)$ protein by
MARylation of an arginine residue, thus maintaining $\mathrm{G}_{\mathrm{S}}$ $\alpha^{\prime}$ s active form. This results in accumulation of intracellular cAMP, ultimately leading to abnormalities in fluid and electrolyte transport that are the hallmark of Vibrio cholera pathogenesis (Vanden Broeck et al. 2007; Catara et al. 2019). Arh1 $1^{-/}$mice exhibit enhanced sensitivity to the toxin with significantly increased fluid accumulation in the intestinal loops (Kato et al. 2007; Watanabe et al. 2018). Moreover, a crosstalk between arginine- and serine-ADP-ribosylation has been recently reported. Specifically, exposure of cultured cells to cholera toxin caused formation of free arginine-ADPr (Arg-ADPr), as also demonstrated earlier in vitro (Oppenheimer 1978), which then specifically inhibits the ARH1 homolog ARH3 with nanomolar affinity (Drown et al. 2018; Rack et al. 2018). ARH1 can degrade free Arg-ADPr in vitro (Moss et al. 1986), and congruously, withdrawal of the exotoxin from the culture media restores ARH3 activity (Drown et al. 2018). Whether inhibition of ARH3 during infection involving cholera toxin-like enzymes is part of the bacterial virulence 
(e.g., by altering the cellular DNA damage response) remains, however, to be clarified.

\section{ARH3}

ARH3 is a ubiquitous protein conserved in Animalia and Capsaspora (Oka et al. 2006). ARH3 localizes to the cytosol, mitochondria, and nucleus, and experimental data suggest that the precise subcellular distribution may depend on cell type as well as cellular requirement (Oka et al. 2006; Niere et al. 2012; Mashimo et al. 2013). For example, ARH3 was detected in the nuclei of mouse brain and MEFs, but was absent in the ones of HepG2 cells (Oka et al. 2006; Mashimo et al. 2013; Bonfiglio et al. 2017), which suggests that ARH3 may have cell type-specific functions.

ARH3 has a key role in the hydrolysis of serine-linked $\mathrm{ADPr}$ that is used in regulation of numerous proteins controlling genome stability in higher organisms (Abplanalp et al. 2017; Bonfiglio et al. 2017; Fontana et al. 2017; Palazzo et al. 2018). In vitro studies with all known (ADP-ribosyl)hydrolases indicate that for this function no backup pathway exists in mammalian cells (Fontana et al. 2017). In addition, hydrolysis of PAR chains as well as OAADPR has been reported for ARH3 (Oka et al. 2006; Kasamatsu et al. 2011; Mashimo and Moss 2016; Fontana et al. 2017), but in this case, alternative hydrolases exist in the cells. PAR-removing activity of ARH3 has been linked to the regulation of parthanatos, a special type of apoptosis (Mashimo et al. 2013; Dawson et al. 2017; Robinson et al. 2019).

The partial redundancy between PARG and ARH3 and the preference for serine-linkages, the most prevalently modified residue in the DNA damage response, suggests a prominent role for those enzymes in the maintenance of genome stability (Mashimo et al. 2013, 2019; Tanuma et al. 2016; Fontana et al. 2017; Palazzo et al. 2018). The increased sensitivity of human and mouse ARH3-deficient cells to hydrogen peroxide-induced cell death supports this theory (Tanuma et al. 2016; Palazzo et al. 2018). Loss-of-function mutations in $A R H 3$ were linked to the pathogenesis of a rare recessive autosomal neurodegenerative disorder (Danhauser et al. 2018; Ghosh et al. 2018), suggesting that ARH3 contributes to the protection of neurons from endogenous ROS. In contrast, the mitochondrial function of ARH3 remains elusive, but current observations support two possibilities: First, ARH3 can degrade ADP-ribosylation artificially targeted to the mitochondrial matrix, and hence may be responsible for potential endogenous ADP-ribosylation in this compartment (Niere et al. 2012). Second, the ability to degrade OAADPr suggests a role of ARH3 in metabolite salvage and NAD recycling (Dölle et al. 2013).

\section{$\operatorname{DraG}$}

Several bacteria as well as a few archaea, collectively termed diazotrophs, have the ability to convert atmospheric, molecular nitrogen into ammonia, thus making it available for the biosphere. Due to the high energetic costs associated with this process, its tight regulation is crucial. Some diazotrophs control the pivotal nitrogenase complex by reversible ADP-ribosylation of the Feprotein, also known as the dinitrogenase reductase component. Through dedicated investigation over the last decades, this system has become one of the best-studied reversible ADP-ribosylation signaling pathways. The Fe-protein homodimer is ADP-ribosylated at a single arginine residue (Arg101 in Rhodospirillum rubrum DraG [RruDraG]) by the ARTC family member DraT (Pope et al. 1985; Ma and Ludden 2001). This prevents formation of the nitrogenase complex, which consequently reduces nitrogen fixation. The modification is reversed by (ADP-ribosyl-[dinitrogenase reductase])hydrolase DraG (Ludden and Burris 1976; Saari et al. 1984). Furthermore, the system is controlled by members of the $\mathrm{P}_{\mathrm{II}}$ nitrogen regulatory protein family, which directly and indirectly sense a variety of negative stimuli, including high ammonia or glutamine, low cellular energy, or absence of light (Huergo et al. 2012; Nordlund and Högbom 2013). The cellular energy status is "read" by the $\mathrm{P}_{\mathrm{II}}$ proteins $\mathrm{G} \operatorname{lnB}$ and $\mathrm{G} \operatorname{lnK}$ (orthologous also called GlnZ), which competitively bind ATP and ADP in a cleft at the homotrimer interphase (Xu et al. 1998; Jiang and Ninfa 2007). In vitro studies have shown that in the ADP-bound state GlnB associates with DraT, which results in its activation. Concurrently, the $\mathrm{P}_{\mathrm{II}}$ protein GlnK:ADP complex associates with DraG, leading to its partial inhibition, and further full inactivation is achieved by association of this ternary complex with the ammonia transporter AtmB, hence sequestering DraG at the cellular membrane (Rajendran et al. 2011; Moure et al. 2019). Jointly, these processes lead to inactivation of the nitrogenase complex. Binding of ATP to GlnB and GlnK is synergistic with 2-oxogluterate, a cellular signal of nitrogen and carbon status, (Jiang and Ninfa 2007) and leads to dissociation of DraT and DraG and activation of the nitrogen fixation pathway (Gerhardt et al. 2012; Nordlund and Högbom 2013). It is noteworthy that this represents only one aspect of nitrogen fixation regulation and the system can be further fine-tuned by uridylylation of the $\mathrm{P}_{\text {II }}$ proteins as well as transcriptional regulation of components of the nitrogen fixation pathway (Huergo et al. 2012; Nordlund and Högbom 2013).

\section{Structure and function of ARH enzymes}

Structurally, ARH proteins are compact and globular with a central core motif consisting of 13 orthogonal $\alpha$-helices and a variable number of auxiliary helices depending on the organism and type (e.g., total number of helices: 25 in hARH1 [PDB 6G28], 22 in hARH3 [PDB 2FOZ], and 18 in RruDraG [2WOD]). The overall fold can be subdivided into four quasidomains with the ADP-ribose binding site as well as the catalytic binuclear metal center embedded into their interphase (Fig. 7A; Mueller-Dieckmann et al. 2006; Li et al. 2009; Rack et al. 2018). Coordination of the adenosine moiety differs greatly between the different ARH classes. In DraG, the adenine moiety is coordinated parallel to the protein surface and stacks on top of a conserved tyrosine residue (Tyr212 in RruDraG). Exact 
(ADP-ribosyl)hydrolases

A

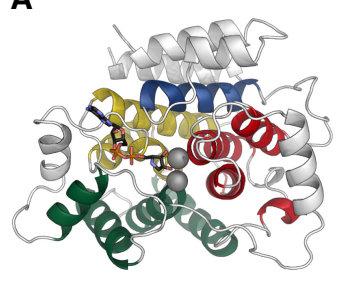

C
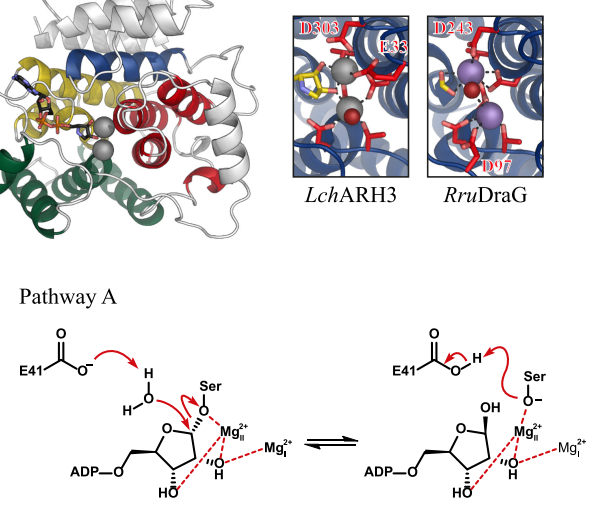

B

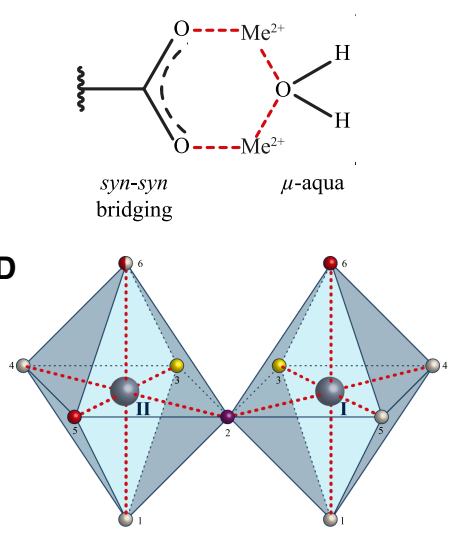

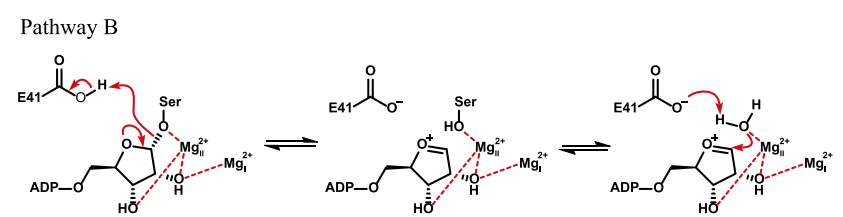

Figure 7. ARH structure and mechanism. $(A)$ The left panel shows a ribbon representation of $L$ chARH3 in complex with the ADPr analog ADP-HPD (CPK coloring; PDB 6HH3). The conserved $13 \alpha$-helical core motif is colored according to quasidomain classification. (Red) A; (green) B; (yellow) C; (blue) D. The right panels show a closeup of the metal coordination of LchARH3 in complex with $\mathrm{Mg}^{2+}($ dark gray) and RruDraG in complex with $\mathrm{Mn}^{2+}$ (mauve). (B) Schematic representation of metal coordination defining the metal-to-metal distance. (C) Schematic representation of the dinuclear metal center. Both metals (dark gray) are octahedral coordinated. Ligands in the first coordination sphere are protein-derived monodentates (white), water (red), $\mu$-aqua (purple), and syn-syn-bridging carboxyl (yellow). Note that axial position 6 of $\mathrm{Me}_{\mathrm{II}}$ can be occupied by either water or glutamate, depending on the conformation of the Glu flap. $(D)$ Potential reaction mechanisms for ARH3-type enzymes. Residue numbers according to hARH3.

positioning is achieved by interaction of the $\mathrm{C} 6$ amine and N7 nitrogen with a conserved ExxA motif (Glu121 in RruDraG). The proximal ribose makes no contacts within the binding cleft and the $2^{\prime}$ and $3^{\prime} \mathrm{OH}$ groups are orientated toward the aqueous environment. In ARH1, the human functional equivalent of $\mathrm{DraG}$, the adenosine is likewise parallel to the protein surface; however, it is shielded from the environment by $\pi-\pi$ stacking with a conserved tyrosine residue (Tyr263 in hARH1). While comparable coordination of the $\mathrm{C} 6$ amine $\mathrm{N} 7$ nitrogen can be observed in the hARH1 structure, the corresponding residues (Ser124 and Gly127 in hARH1) are not well conserved among ARH1's (Rack et al. 2018). The 2' and 3' OH groups of the proximal ribose interact with an ARH1-specific loop region, termed the adenosine-binding loop (Rack et al. 2018). In ARH3, the adenine moiety is orientated perpendicular to the protein surface and stacked between two conserved aromatic residues (Phe143 and Tyr149 in hARH3). As in DraG, the hydroxyl groups of the proximal ribose are exposed to the environment. This orientation is compatible with both endo- and exo-PAR hydrolysis, yet ARH3 endo activity has not been demonstrated so far.

All ARH-type enzymes characterized so far are activated by divalent metal ions coordinated within a binuclear metal center (Nordlund and Norén 1984; Moss et al. 1985; Antharavally et al. 1998; Oka et al. 2006). The residues involved in metal coordination are highly similar, but subclass-specific motifs could be identified (Fig. 2; Mueller-Dieckmann et al. 2006; Berthold et al. 2009; Li et al. 2009; Rack et al. 2018). Dependence on the nature of the divalent-cation was investigated for DraG and ARH3: DraG primarily uses $\mathrm{Mn}^{2+}$, with its activity also supported by $\mathrm{Fe}^{2+}$ and, to a lesser extent, $\mathrm{Co}^{2+}$ and $\mathrm{Mg}^{2+}$ (Nordlund and Norén 1984; Ljungström et al. 1989). In contrast, ARH3 primarily uses $\mathrm{Mg}^{2+}$, but can also be activated by $\mathrm{Mn}^{2+}$ (Rack et al. 2018). No detailed investigation for ARH1 was so far carried out, but it is known that $\mathrm{Mg}^{2+}$ will support its activity (Moss et al. 1985). In the unligated state, the coordination spheres of the two divalent ions are connected by a syn-syn bridging aspartate (Asp316 hARH3) as well as a $\mu$-aqua ligand (Fig. $7 \mathrm{~B}, \mathrm{C}$ ). The latter is displaced upon substrate binding by the $2^{\prime \prime} \mathrm{OH}$ group of the distal ribose both in hARH1 and LchARH3 (Rack et al. 2018). In crystallo, hARH3 can coordinate ADPr even in presence of the $\mu$-aqua ligand albeit with unusually short coordination bonds (Pourfarjam et al. 2018; Wang et al. 2018). Therefore, details of the ligand binding under more physiological conditions remain to be elucidated. However, it is clear that the correct positioning of the substrate in the active site requires both metal ions to be present as well as the cis $2^{\prime \prime}$ and $3^{\prime \prime} \mathrm{OH}$ groups of the distal ribose of the substrate (Pourfarjam et al. 2018; Rack et al. 2018; Wang et al. 2018). The observed arrangement of ligands in the active site also gives a structural explanation for the observed selectivity toward $\alpha-1^{\prime \prime}$-linkages by ARH1 and ARH3 (Moss et al. 1986; Voorneveld et al. 2018). Interestingly, ligand binding was also associated with conformational changes near the active site: One of 
the axial positions of the metal ion II $\left(\mathrm{Me}_{\mathrm{II}}\right)$ shows flexible occupation either by an $\mu$-aqua ligand or glutamic acid residue (Glu41 in hARH3) (Fig. 7C). The loop containing the latter, termed the Glu flap, can undergo conformational changes and it was proposed that coordination of $\mathrm{Mg}^{2+}$ in ARH3 by Glu41 represents as a closed, self-inhibitory state, and that displacement of the loop is a prerequisite for substrate binding (Pourfarjam et al. 2018). In addition to the conformational change, the glutamate residue is crucial for enzymatic activity of ARH3 (Mueller-Dieckmann et al. 2006; Abplanalp et al. 2017; Rack et al. 2018). Beyond this common set of metal coordination features, DraG enzymes contain an additional, highly conserved aspartate (Asp97 in RruDraG; absent in ARH1 and ARH3) in proximity of $\mathrm{Me}_{\mathrm{I}}$. While direct contacts with a cocrystallized $\mathrm{Mn}^{2+}$ ion could be observed in RruDraG (Berthold et al. 2009), the interaction was absent in a structure of the Azospirillum brasilense homolog (AbrDraG) in complex with $\mathrm{Mg}^{2+}$ (Li et al. 2009).

So far only one structure of a DraG-type hydrolase in complex with ADPr is available (Berthold et al. 2009). The electron density of the RruDraG:ADPr complex showed an Amadori product similar to TARG1 (Fig. 6A). However, in contrast to TARG1, the lysine reacting with the active site-bound ADPr is donated from a neighbouring protomer in the crystal packing rather than part of the active site itself. Secondly, it was shown that mutating Glu28 (RruDraG), the structural homolog residue of the Glu flap glutamate, has only a minor effect on catalytic activity, while Asp97 is crucial (Berthold et al. 2009). Comparison of the structures of RruDraG and AbrDraG reveals stark differences in terms of metal coordination: While AbrDraG adopts a coordination similar to ARH1 and ARH3 (see above; Li et al. 2009), in the RruDraG structure the geometry appears to be rotated by $\sim 90^{\circ}$, which results in an axial positioning of the $\mu$-aqua ligand (Fig. 7A,C). In this conformation, the $\mu$-aqua can act as a nucleophile attacking the Schiff base intermediate at $\mathrm{Cl}^{\prime \prime}$ (Berthold et al. 2009). However, the geometry observed in the RruDraG crystal structure does not include a bridging carboxyl group as predicted from earlier electron spin resonance measurements and observed in all other ARH structures (Antharavally et al. 1998; Mueller-Dieckmann et al. 2006; Li et al. 2009; Pourfarjam et al. 2018; Rack et al. 2018; Wang et al. 2018). While details of the DraG mechanism remain elusive, the data point to a prominent role of $\mathrm{Me}_{\mathrm{I}}$ in the reaction mechanism.

ARH1, the functional homolog of DraG, is mechanistically even less understood, but first structural insights have been gained recently (Rack et al. 2018). Its structural features are a hybrid of DraG and ARH3 with the absence of the DraG-specific aspartate (Asp97 in RruDraG; similar to ARH3) as well as increased constrains on the Glu flap flexibility (similar to DraG) (Pourfarjam et al. 2018; Rack et al. 2018). Further studies are needed to understand the hydrolytic mechanism and reveal how far the similarities between ARH1 and the other ARH classes stretch.

The recently solved structures of ARH3 lead to the proposal of different catalytic mechanisms (Pourfarjam et al.
2018; Rack et al. 2018; Wang et al. 2018). Absence of the $\mu$-aqua in ligand-substituted ARH3 structures indicates that it is dispensable for the catalytic mechanism (Rack et al. 2018). However, the available data point toward a closer engagement of the substrate with $\mathrm{Mg}_{\mathrm{II}}$ and a more structural role for $\mathrm{Mg}_{\mathrm{I}}$ (Pourfarjam et al. 2018; Rack et al. 2018). Furthermore, computational modeling and biochemical evidence suggest that the axial water in position 6 (Fig. 7C) is displaced with the $\mathrm{Cl}^{\prime \prime}$ substituent, which is either the O-glycosidic serine linkage or $1^{\prime \prime}$ scissile bond of PAR. In this conformation, the $\beta$ face of the distal ribose would be accessible for a nucleophilic attack of a Glu flap-activated water molecule. This would lead to an $\mathrm{S}_{\mathrm{N}} 2$-type reaction intermediate and formation of an oxyanion (Fig. 7D). Alternatively, direct protonation of the leaving group by Glu41 is possible and would result in the formation of an oxocarbenium intermediate (Fig. 7D). Further studies focusing on the interaction with true substrates are needed to elucidate the details of the reaction mechanism.

\section{Reversal of nucleic acid ADP-ribosylation}

Within the realm of ADP-ribosylation signaling, modification of DNA and RNA phosphor-termini is a newly emerging field of study (Talhaoui et al. 2016; Munnur and Ahel 2017; Munir et al. 2018b; Munnur et al. 2019). While the cellular functions are as yet elusive, the association of this modification with DNA repair as well as antiviral PARPs suggests functions in DNA damage repair and antiviral defence. One possibility is that DNA ADPribosylation may act as a reaction intermediate similar to DNA adenylation during DNA ligation (Lehnman 1974; Pascal 2008; Tanabe et al. 2015). This hypothesis is particularly interesting, as a recent study suggests that human DNA ligase IV, involved in damage repair, can use $\mathrm{NAD}^{+}$(Chen and Yu 2019). Alternatively, capping of $5^{\prime}$ phosphates could have a protective function to preserve the phosphorylation until the required repair factors are assembled at the damage site. In contrast, presence of a $3^{\prime}$-phosphate can interfere with efficient repair and it has been suggested that $E$. coli primes such position for repair by attachment of a guanyl-cap (Chauleau et al. 2015). As for RNA, ADP-ribosylation may contribute to the recognition and/or processing of exogenous and hazardous RNAs; e.g., transposon-derived noncoding or viral RNAs.

Regardless of the exact physiological role, the modification of $3^{\prime}$ - and $5^{\prime}$-phosphor termini is reversible by the action of PARG, MacroD1/2, TARG1, and ARH3 (Munnur et al. 2019). This diversity of enzymes capable of removal may be surprising given the diversity of hydrolytic mechanisms discussed above. However, this may at least partially be the result of the inherent properties of the enzymes and the substrate: (1) a high degree of accessibility of DNA/RNA ends relative to most modifications confined within a protein structure; (2) formation of the phosphate product is favorable in comparison with other reaction intermediates, thus supporting hydrolysis; and (3) ARH3 as well as macrodomains bind ADPr with high 
affinity and hence are predicted to interact with ADPr adducts readily as long as the linked group does not clash with the structure of the hydrolase. Together, the relative nonspecificity of ADPr hydrolysis from nucleic acid termini suggests that it is regulated through recruitment or exclusion of hydrolases from the cellular context in which this modification occurs, but further studies are needed to elucidate the exact similarities and differences in the hydrolysis catalyzed by the various enzymes as well as the exact nature of their regulation.

\section{Conclusions and perspectives}

The examples discussed in this review reflect the increasingly compelling view that (ADP-ribosyl)hydrolases deserve a more prominent role in the investigation of ADP-ribosyl signaling. Understanding their molecular function and substrate specificities will allow us to link them more conclusively to the specific ARTs and thus create a direct functional relationship between "readers" and "writers." Beyond the immediate biochemical connection, it is our hope that future studies will use these links to elucidate the role of the hydrolases in their specific signaling pathways. In this context, it is important to note that the study of hydrolases should be extended beyond the human realm since many (ADP-ribosyl)hydrolases in plants, pathogenic organisms, and model systems among others have still unclear functions (de Souza and Aravind 2012; Perina et al. 2014; Aravind et al. 2015; Zhang et al. 2015a; Gunn et al. 2016; Haikarainen and Lehtiö 2016; Lalić et al. 2016; Zapata-Pérez et al. 2017).

Future efforts in the development of small molecule inhibitors will hopefully produce new probes to study the (patho-)physiological roles of these fascinating enzymes as well as lead to new drugs with therapeutic applications. The potential of such an approach was highlighted over recent years with the development of PARG inhibitors finding their application in cancer therapy (James et al. 2016; Gravells et al. 2017; Waszkowycz et al. 2018).

\section{Acknowledgments}

We apologize to all colleagues whose work could not be included because of space restrictions. We thank Antonio Ariza, Kerryanne Crawford, and Marion Schuller for critical reading of the manuscript. L.P. is grateful to Domenico Grieco and Rosa Marina Melillo (University of Naples "Federico $\mathrm{II}^{\prime}$ ) for helpful discussions and encouragement. L.P. acknowledges support from the Italian Foundation for Cancer Research (FIRC; project code 14895 ) and the POR Campania FESR 2014/2020-Progetto SATIN. I.A.'s laboratory is supported by the Wellcome Trust (101794 and 210634); Biotechnology and Biological Sciences Research Council (BB/R007195/1), and Cancer Research United Kingdom (C35050/A22284).

\section{References}

Aasland R, Abrams C, Ampe C, Ball LJ, Bedford MT, Cesareni G, Gimona M, Hurley JH, Jarchau T, Lehto VP, et al. 2002. Nor- malization of nomenclature for peptide motifs as ligands of modular protein domains. FEBS Lett 513: 141-144. doi:10 .1016/S0014-5793/01)03295-1

Abplanalp J, Leutert M, Frugier E, Nowak K, Feurer R, Kato J, Kistemaker HVA, Filippov DV, Moss J, Caflisch A, et al. 2017. Proteomic analyses identify ARH3 as a serine mono-ADPribosylhydrolase. Nat Commun 8: 2055. doi:10.1038/s41467017-02253-1

Abraham R, Hauer D, McPherson RL, Utt A, Kirby IT, Cohen MS, Merits A, Leung AKL, Griffin DE. 2018. ADP-ribosyl-binding and hydrolase activities of the alphavirus nsP3 macrodomain are critical for initiation of virus replication. Proc Natl Acad Sci 115: E10457-E10466. doi:10.1073/pnas.1812130115

Agnew T, Munnur D, Crawford K, Palazzo L, Mikoč A, Ahel I. 2018. MacroD1 is a promiscuous ADP-ribosyl hydrolase localized to mitochondria. Front Microbiol 9: 20. doi:10.3389/ fmicb.2018.00020

Ahel D, Horejsi Z, Wiechens N, Polo SE, Garcia-Wilson E, Ahel I, Flynn H, Skehel M, West SC, Jackson SP, et al. 2009. Poly (ADP-ribose)-dependent regulation of DNA repair by the chromatin remodeling enzyme ALC1. Science 325: 1240-1243. doi:10.1126/science.1177321

Allen MD, Buckle AM, Cordell SC, Löwe J, Bycroft M. 2003. The crystal structure of AF1521 a protein from Archaeoglobus fulgidus with homology to the non-histone domain of macroH2A. J Mol Biol 330: 503-511. doi:10.1016/S0022-2836(03) 00473-X

Alvarez-Gonzalez R, Althaus FR. 1989. Poly(ADP-ribose) catabolism in mammalian cells exposed to DNA-damaging agents. Mutat Res 218: 67-74. doi:10.1016/0921-8777/89|90012-8

Alvarez-Gonzalez R, Jacobson MK. 1987. Characterization of polymers of adenosine diphosphate ribose generated in vitro and in vivo. Biochemistry 26: 3218-3224. doi:10.1021/ bi00385a042

Amé JC, Spenlehauer C, de Murcia G. 2004. The PARP superfamily. BioEssays 26: 882-893. doi:10.1002/bies.20085

Anney R, Klei L, Pinto D, Regan R, Conroy J, Magalhaes TR, Correia C, Abrahams BS, Sykes N, Pagnamenta AT, et al. 2010. A genome-wide scan for common alleles affecting risk for autism. Hum Mol Genet 19: 4072-4082. doi:10.1093/hmg/ddq307

Antharavally BS, Poyner RR, Ludden PW. 1998. EPR spectral evidence for a binuclear $\mathrm{Mn}$ (II) center in dinitrogenase reductase-activating glycohydrolase from Rhodospirillum rubrum. I Am Chem Soc 120: 8897-8898. doi:10.1021/ ja9818912

Appel CD, Feld GK, Wallace BD, Williams RS. 2016. Structure of the sirtuin-linked macrodomain SAV0325 from Staphylococcus aureus. Protein Sci. 25: 1682-1691. doi:10.1002/pro.2974

Aravind L, Zhang D, de Souza RF, Anand S, Iyer LM. 2015. The natural history of ADP-ribosyltransferases and the ADP-ribosylation system. Curr Top Microbiol Immunol 384: 3-32.

Atasheva S, Akhrymuk M, Frolova EI, Frolov I. 2012. New PARP gene with an anti-alphavirus function. J Virol 86: 8147-8160. doi:10.1128/JVI.00733-12

Atasheva S, Frolova EI, Frolov I. 2014. Interferon-stimulated poly (ADP-Ribose) polymerases are potent inhibitors of cellular translation and virus replication. I Virol 88: 2116-2130. doi:10.1128/JVI.03443-13

Autism Spectrum Disorders Working Group of The Psychiatric Genomics Consortium 2017. Meta-analysis of GWAS of over 16,000 individuals with autism spectrum disorder highlights a novel locus at 10q24.32 and a significant overlap with schizophrenia. Mol Autism 8: 21. doi:10.1186/s13229017-0137-9 
Banerjee A, Munir A, Abdullahu L, Damha MJ, Goldgur Y, Shuman S. 2019. Structure of tRNA splicing enzyme Tpt1 illuminates the mechanism of RNA 2'- $\mathrm{PO}_{4}$ recognition and ADPribosylation. Nat Commun 10: 218. doi:10.1038/s41467-01808211-9

Barkauskaite E, Brassington A, Tan ES, Warwicker J, Dunstan MS, Banos B, Lafite P, Ahel M, Mitchison TJ, Ahel I, et al. 2013. Visualization of poly(ADP-ribose) bound to PARG reveals inherent balance between exo- and endo-glycohydrolase activities. Nat Commun 4: 2164. doi:10.1038/ncomms3164

Barkauskaite E, Jankevicius G, Ahel I. 2015. Structures and mechanisms of enzymes employed in the synthesis and degradation of PARP-dependent protein ADP-ribosylation. Mol Cell 58: 935-946. doi:10.1016/j.molcel.2015.05.007

Bartlett E, Bonfiglio JJ, Prokhorova E, Colby T, Zobel F, Ahel I, Matic I. 2018. Interplay of histone marks with serine ADPribosylation. Cell Rep 24: 3488-3502.e5. doi:10.1016/j.celrep 2018.08.092

Belousova EA, Ishchenko AA, Lavrik OI. 2018. Dna is a new target of Parp3. Sci Rep 8: 4176. doi:10.1038/s41598-018-22673-3

Berthold CL, Wang H, Nordlund S, Hogbom M. 2009. Mechanism of ADP-ribosylation removal revealed by the structure and ligand complexes of the dimanganese mono-ADP-ribosylhydrolase DraG. Proc Natl Acad Sci 106: 14247-14252. doi:10.1073/ pnas.0905906106

Bhogaraju S, Kalayil S, Liu Y, Bonn F, Colby T, Matic I, Dikic I. 2016. Phosphoribosylation of ubiquitin promotes serine ubiquitination and impairs conventional ubiquitination. Cell 167: 1636-1649.e13. doi:10.1016/j.cell.2016.11.019

Bindesbøll C, Tan S, Bott D, Cho T, Tamblyn L, MacPherson L, Grønning-Wang L, Nebb HI, Matthews J. 2016. TCDD-inducible poly-ADP-ribose polymerase (TIPARP/PARP7) monoADP-ribosylates and co-activates liver $\mathrm{X}$ receptors. Biochem J 473: 899-910. doi:10.1042/BJ20151077

Bock FJ, Chang P. 2016. New directions in poly(ADP-ribose) polymerase biology. FEBS I 283: 4017-4031. doi:10.1111/febs .13737

Bockwoldt M, Houry D, Niere M, Gossmann TI, Reinartz I, Schug A, Ziegler M, Heiland I. 2019. Identification of evolutionary and kinetic drivers of NAD-dependent signaling. Proc Natl Acad Sci 116: 15957-15966. doi:10.1073/pnas.1902346116

Bonfiglio JJ, Fontana P, Zhang Q, Colby T, Gibbs-Seymour I, Atanassov I, Bartlett E, Zaja R, Ahel I, Matic I. 2017. Serine ADPribosylation depends on HPF1. Mol Cell 65: 932-940.e6. doi:10.1016/j.molcel.2017.01.003

Brochu G, Duchaine C, Thibeault L, Lagueux J, Shah GM, Poirier GG. 1994. Mode of action of poly(ADP-ribose) glycohydrolase. Biochim Biophys Acta 1219: 342-350. doi:10.1016/0167-4781 (94)90058-2

Bruner SD, Norman DP, Verdine GL. 2000. Structural basis for recognition and repair of the endogenous mutagen 8-oxoguanine in DNA. Nature 403: 859-866. doi:10.1038/35002510

Bütepage M, Preisinger C, von Kriegsheim A, Scheufen A, Lausberg E, Li J, Kappes F, Feederle R, Ernst S, Eckei L, et al. 2018. Nucleolar-nucleoplasmic shuttling of TARG1 and its control by DNA damage-induced poly-ADP-ribosylation and by nucleolar transcription. Sci Rep 8: 6748. doi:10.1038/ s41598-018-25137-w

Carter-O'Connell I, Jin H, Morgan RK, Zaja R, David LL, Ahel I, Cohen MS. 2016. Identifying family-member-specific targets of mono-ARTDs by using a chemical genetics approach. Cell Rep 14: 621-631. doi:10.1016/j.celrep.2015.12.045

Carter-O'Connell I, Vermehren-Schmaedick A, Jin H, Morgan RK, David LL, Cohen MS. 2018. Combining chemical genetics with proximity-dependent labeling reveals cellular targets of
poly(ADP-ribose) polymerase 14 (PARP14). ACS Chem Biol 13: 2841-2848. doi:10.1021/acschembio.8b00567

Catara G, Corteggio A, Valente C, Grimaldi G, Palazzo L. 2019. Targeting ADP-ribosylation as an antimicrobial strategy. Biochem Pharmacol 167: 13-26. doi:10.1016/j.bcp.2019.06.001

Chauleau M, Das U, Shuman S. 2015. Effects of $\mathrm{DNA}_{3^{\prime}} \mathrm{pp}_{5^{\prime}}$ G capping on $3^{\prime}$ end repair reactions and of an embedded pyrophosphate-linked guanylate on ribonucleotide surveillance. Nucleic Acids Res 43: 3197-3207. doi:10.1093/nar/gkv179

Chen SH, Yu X. 2019. Human DNA ligase IV is able to use NAD+ as an alternative adenylation donor for DNA ends ligation. Nucleic Acids Res 47: 1321-1334. doi:10.1093/nar/gky1202

Chen D, Vollmar M, Rossi MN, Phillips C, Kraehenbuehl R, Slade D, Mehrotra PV, von Delft F, Crosthwaite SK, Gileadi O, et al. 2011. Identification of macrodomain proteins as novel $O$-acetyl-ADP-ribose deacetylases. J Biol Chem 286: 13261-13271. doi:10.1074/jbc.M110.206771

Chen Q, Kassab MA, Dantzer F, Yu X. 2018. PARP2 mediates branched poly ADP-ribosylation in response to DNA damage. Nat Commun 9: 3233. doi:10.1038/s41467-018-05588-5

Cortes U, Tong WM, Coyle DL, Meyer-Ficca ML, Meyer RG, Petrilli V, Herceg Z, Jacobson EL, Jacobson MK, Wang ZQ. 2004. Depletion of the 110-kilodalton isoform of poly(ADP-ribose) glycohydrolase increases sensitivity to genotoxic and endotoxic stress in mice. Mol Cell Biol 24: 7163-7178. doi:10 $.1128 /$ MCB.24.16.7163-7178.2004

Cozzi A, Cipriani G, Fossati S, Faraco G, Formentini L, Min W, Cortes U, Wang ZQ, Moroni F, Chiarugi A. 2006. Poly/ADP-ribose) accumulation and enhancement of postischemic brain damage in $110-\mathrm{kDa}$ poly(ADP-ribose) glycohydrolase null mice. I Cereb Blood Flow Metab 26: 684-695. doi:10.1038/sj .jcbfm.9600222

Crawford K, Bonfiglio JJ, Mikoč A, Matic I, Ahel I. 2018. Specificity of reversible ADP-ribosylation and regulation of cellular processes. Crit Rev Biochem Mol Biol 53: 64-82. doi:10 $.1080 / 10409238.2017 .1394265$

D'Amours D, Desnoyers S, D'Silva I, Poirier GG. 1999. Poly|ADPribosyl)ation reactions in the regulation of nuclear functions. Biochem J 342: 249-268. doi:10.1042/bj3420249

Danhauser K, Alhaddad B, Makowski C, Piekutowska-Abramczuk D, Syrbe S, Gomez-Ospina N, Manning MA, KosteraPruszczyk A, Krahn-Peper C, Berutti R, et al. 2018. Bi-allelic ADPRHL2 mutations cause neurodegeneration with developmental delay, Ataxia, and Axonal neuropathy. Am J Hum Genet 103: 817-825. doi:10.1016/j.ajhg.2018.10.005

Daugherty MD, Young JM, Kerns JA, Malik HS. 2014. Rapid evolution of PARP genes suggests a broad role for ADP-ribosylation in host-virus conflicts. PLoS Genet 10: e1004403. doi:10 .1371/journal.pgen.1004403

Dawson NL, Lewis TE, Das S, Lees JG, Lee D, Ashford P, Orengo CA, Sillitoe I. 2017. CATH: an expanded resource to predict protein function through structure and sequence. Nucleic Acids Res 45: D289-D295. doi:10.1093/nar/gkw1098

de Souza RF, Aravind L. 2012. Identification of novel components of NAD-utilizing metabolic pathways and prediction of their biochemical functions. Mol Biosyst 8: 1661-1677. doi:10 $.1039 / \mathrm{c} 2 \mathrm{mb05487f}$

Dölle C, Rack JG, Ziegler M. 2013. NAD and ADP-ribose metabolism in mitochondria. FEBS / 280: 3530-3541. doi:10.1111/ febs. 12304

Drown BS, Shirai T, Rack JGM, Ahel I, Hergenrother PJ. 2018. Monitoring poly(ADP-ribosyl)glycohydrolase activity with a continuous fluorescent substrate. Cell Chem Biol 25: 15621570.e19. doi:10.1016/j.chembiol.2018.09.008 
Dunstan MS, Barkauskaite E, Lafite P, Knezevic CE, Brassington A, Ahel M, Hergenrother PJ, Leys D, Ahel I. 2012. Structure and mechanism of a canonical poly(ADP-ribose) glycohydrolase. Nat Commun 3: 878. doi:10.1038/ncomms1889

Eckei L, Krieg S, Bütepage M, Lehmann A, Gross A, Lippok B, Grimm AR, Kümmerer BM, Rossetti G, Lüscher B, et al. 2017. The conserved macrodomains of the non-structural proteins of Chikungunya virus and other pathogenic positive strand RNA viruses function as mono-ADP-ribosylhydrolases. Sci Rep 7: 41746. doi:10.1038/srep41746

Egloff MP, Malet H, Putics A, Heinonen M, Dutartre H, Frangeul A, Gruez A, Campanacci V, Cambillau C, Ziebuhr J, et al. 2006. Structural and functional basis for ADP-ribose and poly(ADP-ribose) binding by viral macro domains. J Virol 80: 8493-8502. doi:10.1128/JVI.00713-06

Fabrizio G, Di Paola S, Stilla A, Giannotta M, Ruggiero C, Menzel S, Koch-Nolte F, Sallese M, Di Girolamo M. 2015. ARTC1mediated ADP-ribosylation of GRP78/BiP: a new player in endoplasmic-reticulum stress responses. Cell Mol Life Sci 72: 1209-1225. doi:10.1007/s00018-014-1745-6

Fehr AR, Channappanavar R, Jankevicius G, Fett C, Zhao JC, Athmer J, Meyerholz DK, Ahel I, Perlman S. 2016. The conserved coronavirus macrodomain promotes virulence and suppresses the innate immune response during severe acute respiratory syndrome coronavirus infection. MBio 7: e01721. doi:10.1128/mBio.01721-16

Fehr AR, Jankevicius G, Ahel I, Perlman S. 2018. Viral macrodomains: unique mediators of viral replication and pathogenesis. Trends Microbiol 26: 598-610. doi:10.1016/j.tim.2017.11.011

Feijs KL, Kleine H, Braczynski A, Forst AH, Herzog N, Verheugd P, Linzen U, Kremmer E, Lüscher B. 2013. ARTD10 substrate identification on protein microarrays: regulation of GSK3 $\beta$ by mono-ADP-ribosylation. Cell Commun Signal 11: 5. doi:10 .1186/1478-811X-11-5

Feng X, Koh DW. 2013. Roles of poly(ADP-ribose) glycohydrolase in DNA damage and apoptosis. Int Rev Cell Mol Biol 304: 227-281. doi:10.1016/B978-0-12-407696-9.00005-1

Fontana P, Bonfiglio JJ, Palazzo L, Bartlett E, Matic I, Ahel I. 2017. Serine ADP-ribosylation reversal by the hydrolase ARH3. Elife 6: e28533. doi:10.7554/eLife.28533

Fujimoto A, Furuta M, Totoki Y, Tsunoda T, Kato M, Shiraishi Y, Tanaka H, Taniguchi H, Kawakami Y, Ueno M, et al. 2016. Whole-genome mutational landscape and characterization of noncoding and structural mutations in liver cancer. Nat Genet 48: 500-509. doi:10.1038/ng.3547

Gagné JP, Shah RG, Poirier GG. 2001. Analysis of ADP-ribose polymer sizes in intact cells. Mol Cell Biochem 224: 183185. doi:10.1023/A:1011910329010

Gerhardt EC, Araújo LM, Ribeiro RR, Chubatsu LS, Scarduelli M, Rodrigues TE, Monteiro RA, Pedrosa FO, Souza EM, Huergo LF. 2012. Influence of the ADP/ATP ratio, 2-oxoglutarate and divalent ions on Azospirillum brasilense PII protein signalling. Microbiology 158: 1656-1663. doi:10.1099/mic.0 .058446-0

Ghosh SG, Becker K, Huang H, Dixon-Salazar T, Chai G, Salpietro V, Al-Gazali L, Waisfisz Q, Wang H, Vaux KK, et al. 2018. Biallelic mutations in ADPRHL2, encoding ADP-ribosylhydrolase 3, lead to a degenerative pediatric stress-induced epileptic ataxia syndrome. Am J Hum Genet 103: 431-439. doi:10.1016/j.ajhg.2018.07.010

Gibbs-Seymour I, Fontana P, Rack JGM, Ahel I. 2016. HPF1/ C4orf27 is a PARP-1-interacting protein that regulates PARP-1 ADP-ribosylation activity. Mol Cell 62: 432-442. doi:10.1016/j.molcel.2016.03.008
Golia B, Moeller GK, Jankevicius G, Schmidt A, Hegele A, Preißer J, Tran ML, Imhof A, Timinszky G. 2017. ATM induces MacroD2 nuclear export upon DNA damage. Nucleic Acids Res 45: 244-254. doi:10.1093/nar/gkw904

Gossmann TI, Ziegler M. 2014. Sequence divergence and diversity suggests ongoing functional diversification of vertebrate NAD metabolism. DNA Repair 23: 39-48. doi:10.1016/j .dnarep.2014.07.005

Gottschalk AJ, Timinszky G, Kong SE, Jin J, Cai Y, Swanson SK, Washburn MP, Florens L, Ladurner AG, Conaway JW, et al. 2009. Poly(ADP-ribosyl)ation directs recruitment and activation of an ATP-dependent chromatin remodeler. Proc Natl Acad Sci 106: 13770-13774. doi:10.1073/pnas.0906920106

Gouw M, Michael S, Sámano-Sánchez H, Kumar M, Zeke A, Lang B, Bely B, Chemes LB, Davey NE, Deng Z, et al. 2018. The eukaryotic linear motif resource - 2018 update. Nucleic Acids Res 46: D428-D434. doi:10.1093/nar/gkx1077

Gravells P, Grant E, Smith KM, James DI, Bryant HE. 2017. Specific killing of DNA damage-response deficient cells with inhibitors of poly(ADP-ribose) glycohydrolase. DNA Repair 52: 81-91. doi:10.1016/j.dnarep.2017.02.010

Griffin JE, Gawronski JD, Dejesus MA, Ioerger TR, Akerley BJ, Sassetti CM. 2011. High-resolution phenotypic profiling defines genes essential for mycobacterial growth and cholesterol catabolism. PLOS Pathog 7: e1002251. doi:10.1371/journal .ppat.1002251

Grimaldi G, Catara G, Palazzo L, Corteggio A, Valente C, Corda D. 2019. PARPs and PAR as novel pharmacological targets for the treatment of stress granule-associated disorders. Biochem Pharmacol 167: 64-75. doi:10.1016/j.bcp.2019.05.019

Grunewald ME, Chen Y, Kuny C, Maejima T, Lease R, Ferraris D, Aikawa M, Sullivan CS, Perlman S, Fehr AR. 2019. The coronavirus macrodomain is required to prevent PARP-mediated inhibition of virus replication and enhancement of IFN expression. PLoS Pathog 15: e1007756. doi:10.1371/journal .ppat.1007756

Gunn AR, Banos-Pinero B, Paschke P, Sanchez-Pulido L, Ariza A, Day J, Emrich M, Leys D, Ponting CP, Ahel I, et al. 2016. The role of ADP-ribosylation in regulating DNA interstrand crosslink repair. J Cell Sci 129: 3845-3858. doi:10.1242/jcs.193375

Guo T, Zuo Y, Qian L, Liu J, Yuan Y, Xu K, Miao Y, Feng Q, Chen $\mathrm{X}$, Jin $\mathrm{L}$, et al. 2019. ADP-ribosyltransferase PARP11 modulates the interferon antiviral response by mono-ADP-ribosylating the ubiquitin E3 ligase $\beta$-TrCP. Nat Microbiol 4: 1872-1884. doi:10.1038/s41564-019-0428-3

Gupte R, Liu Z, Kraus WL. 2017. PARPs and ADP-ribosylation: recent advances linking molecular functions to biological outcomes. Genes Dev 31: 101-126. doi:10.1101/gad.291518.116

Haikarainen T, Lehtiö L. 2016. Proximal ADP-ribose hydrolysis in trypanosomatids is catalyzed by a macrodomain. Sci Rep 6: 24213. doi:10.1038/srep24213

Han WD, Zhao YL, Meng YG, Zang L, Wu ZQ, Li Q, Si YL, Huang $\mathrm{K}, \mathrm{Ba}$ JM, Morinaga $\mathrm{H}$, et al. 2007. Estrogenically regulated LRP16 interacts with estrogen receptor $\alpha$ and enhances the receptor's transcriptional activity. Endocr Relat Cancer 14: 741-753. doi:10.1677/ERC-06-0082

Hendriks IA, Larsen SC, Nielsen ML. 2019. An advanced strategy for comprehensive profiling of ADP-ribosylation sites using mass spectrometry-based proteomics. Mol Cell Proteomics 18: 1010-1026. doi:10.1074/mcp.TIR119.001315

Honjo T, Nishizuka Y, Hayaishi O. 1968. Diphtheria toxin-dependent adenosine diphosphate ribosylation of aminoacyl transferase II and inhibition of protein synthesis. I Biol Chem 243: 3553-3555. 
Huergo LF, Pedrosa FO, Muller-Santos M, Chubatsu LS, Monteiro RA, Merrick M, Souza EM. 2012. PII signal transduction proteins: pivotal players in post-translational control of nitrogenase activity. Microbiology 158: 176-190. doi:10.1099/mic.0 .049783-0

Illuzzi G, Fouquerel E, Amé JC, Noll A, Rehmet K, Nasheuer HP, Dantzer F, Schreiber V. 2014. PARG is dispensable for recovery from transient replicative stress but required to prevent detrimental accumulation of poly(ADP-ribose) upon prolonged replicative stress. Nucleic Acids Res 42: 7776-7792. doi:10.1093/nar/gku505

Imagama S, Abe A, Suzuki M, Hayakawa F, Katsumi A, Emi N, Kiyoi H, Naoe T. 2007. LRP16 is fused to RUNX1 in monocytic leukemia cell line with $\mathrm{t}(11 ; 21)(\mathrm{q} 13 ; \mathrm{q} 22)$. Eur J Haematol 79: 25-31. doi:10.1111/j.1600-0609.2007.00858.x

Ito $\mathrm{H}$, Morishita R, Mizuno M, Kawamura N, Tabata H, Nagata KI. 2018. Biochemical and morphological characterization of a neurodevelopmental disorder-related mono-ADP-ribosylhydrolase, MACRO domain containing 2. Dev Neurosci 40: 278287. doi:10.1159/000492271

James DI, Smith KM, Jordan AM, Fairweather EE, Griffiths LA, Hamilton NS, Hitchin JR, Hutton CP, Jones S, Kelly P, et al. 2016. First-in-class chemical probes against poly(ADP-ribose) glycohydrolase (PARG) inhibit DNA repair with differential pharmacology to olaparib. ACS Chem Biol 11: 3179-3190. doi:10.1021/acschembio.6b00609

Jankevicius G, Hassler M, Golia B, Rybin V, Zacharias M, Timinszky G, Ladurner AG. 2013. A family of macrodomain proteins reverses cellular mono-ADP-ribosylation. Nat Struct Mol Biol 20: 508-514. doi:10.1038/nsmb.2523

Jankevicius G, Ariza A, Ahel M, Ahel I. 2016. The toxin-antitoxin system DarTG catalyzes reversible ADP-ribosylation of DNA. Mol Cell 64: 1109-1116. doi:10.1016/j.molcel.2016.11.014

Jiang P, Ninfa AJ. 2007. Escherichia coli PII signal transduction protein controlling nitrogen assimilation acts as a sensor of adenylate energy charge in vitro. Biochemistry 46: 1297912996. doi:10.1021/bi701062t

Juszczynski P, Kutok JL, Li C, Mitra J, Aguiar RC, Shipp MA. 2006. BAL1 and BBAP are regulated by a gamma interferon-responsive bidirectional promoter and are overexpressed in diffuse large B-cell lymphomas with a prominent inflammatory infiltrate. Mol Cell Biol 26: 5348-5359. doi:10.1128/MCB .02351-05

Karras GI, Kustatscher G, Buhecha HR, Allen MD, Pugieux C, Sait F, Bycroft M, Ladurner AG. 2005. The macro domain is an ADP-ribose binding module. EMBO J 24: 1911-1920. doi:10.1038/sj.emboj.7600664

Kasamatsu A, Nakao M, Smith BC, Comstock LR, Ono T, Kato J, Denu JM, Moss J. 2011. Hydrolysis of O-acetyl-ADP-ribose isomers by ADP-ribosylhydrolase 3. I Biol Chem 286: 21110-21117. doi:10.1074/jbc.M111.237636

Kato J, Zhu J, Liu C, Moss J. 2007. Enhanced sensitivity to cholera toxin in ADP-ribosylarginine hydrolase-deficient mice. Mol Cell Biol 27: 5534-5543. doi:10.1128/MCB.00302-07

Kato J, Zhu J, Liu C, Stylianou M, Hoffmann V, Lizak MJ, Glasgow CG, Moss J. 2011. ADP-ribosylarginine hydrolase regulates cell proliferation and tumorigenesis. Cancer Res 71: 5327-5335. doi:10.1158/0008-5472.CAN-10-0733

Kato J, Vekhter D, Heath J, Zhu J, Barbieri JT, Moss J. 2015. Mutations of the functional ARH1 allele in tumors from ARH1 heterozygous mice and cells affect ARH1 catalytic activity, cell proliferation and tumorigenesis. Oncogenesis 4: e151. doi:10.1038/oncsis.2015.5

Kaufmann T, Grishkovskaya I, Polyansky AA, Kostrhon S, Kukolj E, Olek KM, Herbert S, Beltzung E, Mechtler K, Peterbauer T, et al. 2017. A novel non-canonical PIP-box mediates PARG interaction with PCNA. Nucleic Acids Res 45: 9741-9759. doi:10.1093/nar/gkx604

Kim KS, Manasherob R, Cohen SN. 2008. YmdB: a stress-responsive ribonuclease-binding regulator of $E$. coli RNase III activity. Genes Dev 22: 3497-3508. doi:10.1101/gad.1729508

Kim IK, Kiefer JR, Ho CM, Stegeman RA, Classen S, Tainer JA, Ellenberger T. 2012. Structure of mammalian poly/ADP-ribose) glycohydrolase reveals a flexible tyrosine clasp as a substrate-binding element. Nat Struct Mol Biol 19: 653-656. doi:10.1038/nsmb.2305

Kim T, Lee J, Kim KS. 2013. Escherichia coli YmdB regulates biofilm formation independently of its role as an RNase III modulator. BMC Microbiol 13: 266. doi:10.1186/1471-2180-13266

Kim M, Kim M, Kim KS. 2017. YmdB-mediated down-regulation of sucA inhibits biofilm formation and induces apramycin susceptibility in Escherichia coli. Biochem Biophys Res Commun 483: 252-257. doi:10.1016/j.bbrc.2016.12.157

Kistemaker HA, Nardozza AP, Overkleeft HS, van der Marel GA, Ladurner AG, Filippov DV. 2016. Synthesis and macrodomain binding of mono-ADP-ribosylated peptides. Angew Chem 55: 10634-10638. doi:10.1002/anie.201604058

Koh DW, Lawler AM, Poitras MF, Sasaki M, Wattler S, Nehls MC, Stoger T, Poirier GG, Dawson VL, Dawson TM. 2004. Failure to degrade poly(ADP-ribose) causes increased sensitivity to cytotoxicity and early embryonic lethality. Proc Natl Acad Sci 101: 17699-17704. doi:10.1073/pnas.0406182101

Lalić J, Posavec Marjanović M, Palazzo L, Perina D, Sablijić I, Žaja R, Colby T, Pleše B, Halasz M, Jankevicius G, et al. 2016. Disruption of macrodomain protein SCO6735 increases antibiotic production in Streptomyces coelicolor. I Biol Chem 291: 23175-23187. doi:10.1074/jbc.M116.721894

Lambrecht MJ, Brichacek M, Barkauskaite E, Ariza A, Ahel I, Hergenrother PJ. 2015. Synthesis of dimeric ADP-ribose and its structure with human poly(ADP-ribose) glycohydrolase. I Am Chem Soc 137: 3558-3564. doi:10.1021/ja512528p

Larsen SC, Hendriks IA, Lyon D, Jensen LJ, Nielsen ML. 2018. Systems-wide analysis of serine ADP-ribosylation reveals widespread occurrence and site-specific overlap with phosphorylation. Cell Rep 24: 2493-2505.e4. doi:10.1016/j.celrep .2018.07.083

Lehnman IR. 1974. DNA ligase: structure, mechanism, and function. Science 186: 790-797. doi:10.1126/science.186.4166.790

Lei J, Kusov Y, Hilgenfeld R. 2018. Nsp3 of coronaviruses: structures and functions of a large multi-domain protein. Antiviral Res 149: 58-74. doi:10.1016/j.antiviral.2017.11.001

Leidecker O, Bonfiglio JJ, Colby T, Zhang Q, Atanassov I, Zaja R, Palazzo L, Stockum A, Ahel I, Matic I. 2016. Serine is a new target residue for endogenous ADP-ribosylation on histones. Nat Chem Biol 12: 998-1000. doi:10.1038/nchembio.2180

Leslie Pedrioli DM, Leutert M, Bilan V, Nowak K, Gunasekera K, Ferrari E, Imhof R, Malmstrom L, Hottiger MO. 2018. Comprehensive ADP-ribosylome analysis identifies tyrosine as an ADP-ribose acceptor site. EMBO Rep 19: e45310. doi:10 $.15252 / \mathrm{embr} .201745310$

Leung AK, Vyas S, Rood JE, Bhutkar A, Sharp PA, Chang P. 2011. Poly(ADP-ribose) regulates stress responses and microRNA activity in the cytoplasm. Mol Cell 42: 489-499. doi:10 .1016/j.molcel.2011.04.015

Leung AKL, McPherson RL, Griffin DE. 2018. Macrodomain ADP-ribosylhydrolase and the pathogenesis of infectious diseases. PLoS Pathog 14: e1006864. doi:10.1371/journal.ppat .1006864 
Leutert M, Menzel S, Braren R, Rissiek B, Hopp AK, Nowak K, Bisceglie L, Gehrig P, Li H, Zolkiewska A, et al. 2018. Proteomic characterization of the heart and skeletal muscle reveals widespread arginine ADP-ribosylation by the ARTC1 ectoenzyme. Cell Rep 24: 1916-1929.e5. doi:10.1016/j.celrep.2018 .07 .048

Li XD, Huergo LF, Gasperina A, Pedrosa FO, Merrick M, Winkler FK. 2009. Crystal structure of dinitrogenase reductase-activating glycohydrolase (DraG) reveals conservation in the ADPribosylhydrolase fold and specific features in the ADP-ribose-binding pocket. J Mol Biol 390: 737-746. doi:10.1016/j .jmb.2009.05.031

Li C, Debing Y, Jankevicius G, Neyts J, Ahel I, Coutard B, Canard B. 2016. Viral macro domains reverse protein ADP-ribosylation. J Virol 90: 8478-8486. doi:10.1128/JVI.00705-16

Li X, Wu Z, An X, Mei Q, Bai M, Hanski L, Li X, Ahola T, Han W. 2017. Blockade of the LRP16-PKR-NF- $\mathrm{kB}$ signaling axis sensitizes colorectal carcinoma cells to DNA-damaging cytotoxic therapy. Elife 6: e27301. doi:10.7554/eLife.27301

Ljungström E, Yates MG, Nordlund S. 1989. Purification of the activating enzyme for the Fe-Protein of Nitrogenase from $\mathrm{AzO}$ spirillum-Brasilense. Biochim Biophys Acta 994: 210-214. doi:10.1016/0167-4838/89|90295-1

Ludden PW, Burris RH. 1976. Activating factor for the iron protein of nitrogenase from Rhodospirillum rubrum. Science 194: 424-426. doi:10.1126/science.824729

Ma Y, Ludden PW. 2001. Role of the dinitrogenase reductase arginine 101 residue in dinitrogenase reductase ADP-ribosyltransferase binding, NAD binding, and cleavage. I Bacteriol 183: 250-256. doi:10.1128/JB.183.1.250-256.2001

Mashimo M, Moss J. 2016. Functional role of ADP-ribosyl-acceptor hydrolase 3 in poly(ADP-ribose) polymerase-1 response to oxidative stress. Curr Protein Pept Sci 17: 633-640. doi:10 $.2174 / 1389203717666160419144603$

Mashimo M, Kato J, Moss J. 2013. ADP-ribosyl-acceptor hydrolase 3 regulates poly (ADP-ribose) degradation and cell death during oxidative stress. Proc Natl Acad Sci 110: 18964 18969. doi:10.1073/pnas.1312783110

Mashimo M, Kato J, Moss J. 2014. Structure and function of the ARH family of ADP-ribosyl-acceptor hydrolases. DNA Repair 23: 88-94. doi:10.1016/j.dnarep.2014.03.005

Mashimo M, Bu X, Aoyama K, Kato J, Ishiwata-Endo H, Stevens LA, Kasamatsu A, Wolfe LA, Toro C, Adams D, et al. 2019. PARP1 inhibition alleviates injury in ARH3-deficient mice and human cells. JCI Insight 4: 124519. doi:10.1172/jci .insight.124519

Matsubara H, Hasegawa S, Fujimura S, Shima T, Sugimura T. 1970. Studies on poly (adenosine diphosphate ribose). V. Mechanism of hydrolysis of poly (adenosine diphosphate ribose) by snake venom phosphodiesterase. I Biol Chem 245: 3606-3611.

McInerney GM, Kedersha NL, Kaufman RJ, Anderson P, Liljeström P. 2005. Importance of eIF $2 \alpha$ phosphorylation and stress granule assembly in alphavirus translation regulation. Mol Biol Cell 16: 3753-3763. doi:10.1091/mbc.e05-02-0124

McPherson RL, Abraham R, Sreekumar E, Ong SE, Cheng SJ, Baxter VK, Kistemaker HA, Filippov DV, Griffin DE, Leung AK. 2017. ADP-ribosylhydrolase activity of Chikungunya virus macrodomain is critical for virus replication and virulence. Proc Natl Acad Sci 114: 1666-1671. doi:10.1073/pnas .1621485114

Meyer RG, Meyer-Ficca ML, Jacobson EL, Jacobson MK. 2003. Human poly(ADP-ribose) glycohydrolase (PARG) gene and the common promoter sequence it shares with inner mito- chondrial membrane translocase 23 (TIM23). Gene 314: 181-190. doi:10.1016/S0378-1119/03)00738-8

Meyer-Ficca ML, Meyer RG, Coyle DL, Jacobson EL, Jacobson MK. 2004. Human poly(ADP-ribose) glycohydrolase is expressed in alternative splice variants yielding isoforms that localize to different cell compartments. Exp Cell Res 297: 521532. doi:10.1016/j.yexcr.2004.03.050

Min W, Cortes U, Herceg Z, Tong WM, Wang ZQ. 2010. Deletion of the nuclear isoform of poly(ADP-ribose) glycohydrolase (PARG) reveals its function in DNA repair, genomic stability and tumorigenesis. Carcinogenesis 31: 2058-2065. doi:10 $.1093 /$ carcin/bgq205

Mohseni M, Cidado J, Croessmann S, Cravero K, Cimino-Mathews A, Wong HY, Scharpf R, Zabransky DJ, Abukhdeir AM, Garay JP, et al. 2014. MACROD2 overexpression mediates estrogen independent growth and tamoxifen resistance in breast cancers. Proc Nat1 Acad Sci 111: 17606-17611. doi:10.1073/ pnas. 1408650111

Mortusewicz O, Fouquerel E, Amé JC, Leonhardt H, Schreiber V. 2011. PARG is recruited to DNA damage sites through poly (ADP-ribose)- and PCNA-dependent mechanisms. Nucleic Acids Res 39: 5045-5056. doi:10.1093/nar/gkr099

Moss J, Jacobson MK, Stanley SJ. 1985. Reversibility of argininespecific mono(ADP-ribosyl)ation: identification in erythrocytes of an ADP-ribose-L-arginine cleavage enzyme. Proc Nat1 Acad Sci 82: 5603-5607. doi:10.1073/pnas.82.17.5603

Moss J, Oppenheimer NJ, West, Jr. RE, Stanley SJ. 1986. Amino acid specific ADP-ribosylation: substrate specificity of an ADP-ribosylarginine hydrolase from turkey erythrocytes. Biochemistry 25: 5408-5414. doi:10.1021/bi00367a010

Moss J, Stanley SI, Nightingale MS, Murtagh JJ, Jr., Monaco L, Mishima K, Chen HC, Williamson KC, Tsai SC. 1992. Molecular and immunological characterization of ADP-ribosylarginine hydrolases. J Biol Chem 267: 10481-10488.

Moure VR, Siöberg CLB, Valdameri G, Nji E, Oliveira MAS, Gerdhardt ECM, Pedrosa FO, Mitchell DA, Seefeldt LC, Huergo LF, et al. 2019. The ammonium transporter AmtB and the PII signal transduction protein GlnZ are required to inhibit DraG in Azospirillum brasilense. FEBS J 286: 1214-1229. doi:10.1111/ febs. 14745

Mueller-Dieckmann C, Kernstock S, Lisurek M, von Kries JP, Haag F, Weiss MS, Koch-Nolte F. 2006. The structure of human ADP-ribosylhydrolase 3 (ARH3) provides insights into the reversibility of protein ADP-ribosylation. Proc Natl Acad Sci 103: 15026-15031. doi:10.1073/pnas.0606762103

Munir A, Abdullahu L, Damha MJ, Shuman S. 2018a. Two-step mechanism and step-arrest mutants of Runella slithyformis $\mathrm{NAD}^{+}$-dependent tRNA 2'-phosphotransferase Tpt1. RNA 24: 1144-1157. doi:10.1261/rna.067165.118

Munir A, Banerjee A, Shuman S. 2018b. NAD ${ }^{+}$-dependent synthesis of a $5^{\prime}$-phospho-ADP-ribosylated RNA/DNA cap by RNA 2'-phosphotransferase Tpt1. Nucleic Acids Res 46: 96179624. doi:10.1093/nar/gky792

Munnur D, Ahel I. 2017. Reversible mono-ADP-ribosylation of DNA breaks. FEBS J 284: 4002-4016. doi:10.1111/febs.14297

Munnur D, Bartlett E, Mikolčević P, Kirby IT, Matthias Rack JG, Mikoč A, Cohen MS, Ahel I. 2019. Reversible ADP-ribosylation of RNA. Nucleic Acids Res 47: 5658-5669. doi:10.1093/ nar/gkz305

Nakano T, Matsushima-Hibiya Y, Yamamoto M, Enomoto S, Matsumoto Y, Totsuka Y, Watanabe M, Sugimura T, Wakabayashi K. 2006. Purification and molecular cloning of a DNA ADP-ribosylating protein, CARP-1, from the edible clam Meretrix lamarckii. Proc Natl Acad Sci 103: 1365213657. doi:10.1073/pnas.0606140103 
Nakano T, Matsushima-Hibiya Y, Yamamoto M, TakahashiNakaguchi A, Fukuda H, Ono M, Takamura-Enya T, Kinashi H, Totsuka Y. 2013. ADP-ribosylation of guanosine by SCO5461 protein secreted from Streptomyces coelicolor. Toxicon 63: 55-63. doi:10.1016/j.toxicon.2012.11.019

Nakano T, Takahashi-Nakaguchi A, Yamamoto M, Watanabe M. 2015. Pierisins and CARP-1: ADP-ribosylation of DNA by ARTCs in butterflies and shellfish. Curr Top Microbiol Immunol 384: 127-149.

Niere M, Kernstock S, Koch-Nolte F, Ziegler M. 2008. Functional localization of two poly(ADP-ribose)-degrading enzymes to the mitochondrial matrix. Mol Cell Biol 28: 814-824. doi:10 .1128/MCB.01766-07

Niere M, Mashimo M, Agledal L, Dölle C, Kasamatsu A, Kato J, Moss J, Ziegler M. 2012. ADP-ribosylhydrolase 3 (ARH3), not poly(ADP-ribose) glycohydrolase (PARG) isoforms, is responsible for degradation of mitochondrial matrix-associated poly(ADP-ribose). I Biol Chem 287: 16088-16102. doi:10 $.1074 /$ jbc.M112.349183

Nordlund S, Högbom M. 2013. ADP-ribosylation, a mechanism regulating nitrogenase activity. FEBS I 280: 3484-3490. doi:10.1111/febs.12279

Nordlund S, Norén A. 1984. Dependence on divalent-cations of the activation of inactive Fe-protein of nitrogenase from Rhodospirillum-Rubrum. Biochim Biophys Acta 791: 21-27. doi:10.1016/0167-4838(84)90276-0

Oka S, Kato J, Moss J. 2006. Identification and characterization of a mammalian 39-kDa poly(ADP-ribose) glycohydrolase. J Biol Chem 281: 705-713. doi:10.1074/jbc.M510290200

Ono T, Kasamatsu A, Oka S, Moss J. 2006. The 39-kDa poly(ADPribose) glycohydrolase ARH3 hydrolyzes O-acetyl-ADP-ribose, a product of the Sir2 family of acetyl-histone deacetylases. Proc Natl Acad Sci 103: 16687-16691. doi:10.1073/ pnas.0607911103

Oppenheimer NJ. 1978. Structural determination and stereospecificity of the choleragen-catalyzed reaction of NAD+ with guanidines. J Biol Chem 253: 4907-4910.

Palazzo L, Ahel I. 2018. PARPs in genome stability and signal transduction: implications for cancer therapy. Biochem Soc Trans 46: 1681-1695. doi:10.1042/BST20180418

Palazzo L, Thomas B, Jemth AS, Colby T, Leidecker O, Feijs KL, Zaja R, Loseva O, Puigvert JC, Matic I, et al. 2015. Processing of protein ADP-ribosylation by Nudix hydrolases. Biochem I 468: 293-301. doi:10.1042/BJ20141554

Palazzo L, Daniels CM, Nettleship JE, Rahman N, McPherson RL, Ong SE, Kato K, Nureki O, Leung AK, Ahel I. 2016. ENPP1 processes protein ADP-ribosylation in vitro. FEBS I 283: 3371-3388. doi:10.1111/febs.13811

Palazzo L, Mikoč A, Ahel I. 2017. ADP-ribosylation: new facets of an ancient modification. FEBS J 284: 2932-2946. doi:10.1111/ febs. 14078

Palazzo L, Leidecker O, Prokhorova E, Dauben H, Matic I, Ahel I. 2018. Serine is the major residue for ADP-ribosylation upon DNA damage. Elife 7: e34334. doi:10.7554/eLife.34334

Pascal JM. 2008. DNA and RNA ligases: structural variations and shared mechanisms. Curr Opin Struct Biol 18: 96-105. doi:10 $.1016 /$ j.sbi.2007.12.008

Paudyal S, Alfonso-Prieto M, Carnevale V, Redhu SK, Klein ML, Nicholson AW. 2015. Combined computational and experimental analysis of a complex of ribonuclease III and the regulatory macrodomain protein, YmdB. Proteins 83: 459-472. doi:10.1002/prot.24751

Perina D, Mikoč A, Ahel J, Ćetković H, Žaja R, Ahel I. 2014. Distribution of protein poly(ADP-ribosyl)ation systems across all domains of life. DNA Repair 23: 4-16. doi:10.1016/j.dnarep .2014.05.003

Peterson FC, Chen D, Lytle BL, Rossi MN, Ahel I, Denu JM, Volkman BF. 2011. Orphan macrodomain protein (human C6orf130) is an O-acyl-ADP-ribose deacylase: solution structure and catalytic properties. J Biol Chem 286: 35955-35965. doi:10.1074/jbc.M111.276238

Pillay N, Tighe A, Nelson L, Littler S, Coulson-Gilmer C, Bah N, Golder A, Bakker B, Spierings DCJ, James DI, et al. 2019. DNA replication vulnerabilities render ovarian cancer cells sensitive to poly(ADP-ribose) glycohydrolase inhibitors. Cancer Cell 35: 519-533.e8. doi:10.1016/j.ccell.2019.02.004

Pope MR, Murrell SA, Ludden PW. 1985. Covalent modification of the iron protein of nitrogenase from Rhodospirillum rubrum by adenosine diphosphoribosylation of a specific arginine residue. Proc Natl Acad Sci 82: 3173-3177. doi:10.1073/ pnas.82.10.3173

Popow J, Schleiffer A, Martinez J. 2012. Diversity and roles of $(\mathrm{t})$ RNA ligases. Cell Mol Life Sci 69: 2657-2670. doi:10.1007/ s00018-012-0944-2

Pourfarjam Y, Ventura J, Kurinov I, Cho A, Moss J, Kim IK. 2018. Structure of human ADP-ribosyl-acceptor hydrolase 3 bound to ADP-ribose reveals a conformational switch that enables specific substrate recognition. I Biol Chem 293: 1235012359. doi:10.1074/jbc.RA118.003586

Puranik NV, Rani R, Singh VA, Tomar S, Puntambekar HM, Srivastava P. 2019. Evaluation of the antiviral potential of halogenated dihydrorugosaflavonoids and molecular modeling with nsP3 protein of Chikungunya virus (CHIKV). ACS Omega 4: 20335-20345. doi:10.1021/acsomega.9b02900

Puvar K, Luo ZQ, Das C. 2019. Uncovering the structural basis of a new twist in protein ubiquitination. Trends Biochem Sci 44: 467-477. doi:10.1016/j.tibs.2018.11.006

Rack JG, Morra R, Barkauskaite E, Kraehenbuehl R, Ariza A, Qu Y, Ortmayer M, Leidecker O, Cameron DR, Matic I, et al. 2015. Identification of a class of protein ADP-ribosylating sirtuins in microbial pathogens. Mol Cell 59: 309-320. doi:10 .1016/j.molcel.2015.06.013

Rack JG, Perina D, Ahel I. 2016. Macrodomains: structure, function, evolution, and catalytic activities. Annu Rev Biochem 85: 431-454. doi:10.1146/annurev-biochem-060815-014935

Rack JGM, Ariza A, Drown BS, Henfrey C, Bartlett E, Shirai T, Hergenrother PJ, Ahel I. 2018. (ADP-ribosyl)hydrolases: structural basis for differential substrate recognition and inhibition. Cell Chem Biol 25: 1533-1546.e12. doi:10.1016/j .chembiol.2018.11.001

Rajendran C, Gerhardt EC, Bjelic S, Gasperina A, Scarduelli M, Pedrosa FO, Chubatsu LS, Merrick M, Souza EM, Winkler FK, et al. 2011. Crystal structure of the GlnZ-DraG complex reveals a different form of PII-target interaction. Proc Natl Acad Sci 108: 18972-18976. doi:10.1073/pnas.1108038108

Ray Chaudhuri A, Ahuja AK, Herrador R, Lopes M. 2015. Poly (ADP-ribosyl) glycohydrolase prevents the accumulation of unusual replication structures during unperturbed $\mathrm{S}$ phase. Mol Cell Biol 35: 856-865. doi:10.1128/MCB.01077-14

Rechkunova NI, Maltseva EA, Lavrik OI. 2019. Post-translational modifications of nucleotide excision repair proteins and their role in the DNA repair. Biochemistry 84: 1008-1020. doi:10 $.1134 /$ S0006297919090037

Rippmann JF, Damm K, Schnapp A. 2002. Functional characterization of the poly(ADP-ribose) polymerase activity of tankyrase 1, a potential regulator of telomere length. J Mol Biol 323: 217-224. doi:10.1016/S0022-2836(02)00946-4

Robinson N, Ganesan R, Hegedûs C, Kovács K, Kufer TA, Virág L. 2019. Programmed necrotic cell death of macrophages: focus 
on pyroptosis, necroptosis, and parthanatos. Redox Biol 26: 101239. doi:10.1016/j.redox.2019.101239

Rosenthal F, Feijs KL, Frugier E, Bonalli M, Forst AH, Imhof R, Winkler HC, Fischer D, Caflisch A, Hassa PO, et al. 2013. Macrodomain-containing proteins are new mono-ADP-ribosylhydrolases. Nat Struct Mol Biol 20: 502-507. doi:10.1038/ nsmb. 2521

Saari LL, Triplett EW, Ludden PW. 1984. Purification and properties of the activating enzyme for iron protein of nitrogenase from the photosynthetic bacterium Rhodospirillum rubrum. J Biol Chem 259: 15502-15508.

Sakthianandeswaren A, Parsons MJ, Mouradov D, MacKinnon RN, Catimel B, Liu S, Palmieri M, Love C, Jorissen RN, Li S, et al. 2018. MACROD2 haploinsufficiency impairs catalytic activity of PARP1 and promotes chromosome instability and growth of intestinal tumors. Cancer Discov 8: 988-1005. doi:10.1158/2159-8290.CD-17-0909

Sassetti CM, Boyd DH, Rubin EJ. 2003. Genes required for mycobacterial growth defined by high density mutagenesis. Mol Microbiol 48: 77-84. doi:10.1046/j.1365-2958.2003.03425.x

Sauve AA, Youn DY. 2012. Sirtuins: NAD ${ }^{+}$-dependent deacetylase mechanism and regulation. Curr Opin Chem Biol 16: 535-543. doi:10.1016/j.cbpa.2012.10.003

Sberro H, Leavitt A, Kiro R, Koh E, Peleg Y, Qimron U, Sorek R. 2013. Discovery of functional toxin/antitoxin systems in bacteria by shotgun cloning. Mol Cell 50: 136-148. doi:10.1016/j .molcel.2013.02.002

Schoggins JW, Wilson SJ, Panis M, Murphy MY, Jones CT, Bieniasz P, Rice CM. 2011. A diverse range of gene products are effectors of the type I interferon antiviral response. Nature 472: 481-485. doi:10.1038/nature09907

Shao Y, Li X, Lu Y, Liu L, Zhao P. 2015. Aberrant LRP16 protein expression in primary neuroendocrine lung tumors. Int I Clin Exp Pathol 8: 6560-6565.

Sharifi R, Morra R, Appel CD, Tallis M, Chioza B, Jankevicius G, Simpson MA, Matic I, Ozkan E, Golia B, et al. 2013. Deficiency of terminal ADP-ribose protein glycohydrolase TARG1/C6orf130 in neurodegenerative disease. EMBO J 32: 1225-1237. doi:10.1038/emboj.2013.51

Shim B, Pacheco-Rodriguez G, Kato J, Darling TN, Vaughan M, Moss J. 2013. Sex-specific lung diseases: effect of oestrogen on cultured cells and in animal models. Eur Respir I 22: 302-311. doi:10.1183/09059180.00002813

Slade D, Dunstan MS, Barkauskaite E, Weston R, Lafite P, Dixon N, Ahel M, Leys D, Ahel I. 2011. The structure and catalytic mechanism of a poly(ADP-ribose) glycohydrolase. Nature 477: 616-620. doi:10.1038/nature10404

Smith SJ, Towers N, Saldanha JW, Shang CA, Mahmood SR, Taylor WR, Mohun TJ. 2016. The cardiac-restricted protein ADPribosylhydrolase-like 1 is essential for heart chamber outgrowth and acts on muscle actin filament assembly. Dev Biol 416: 373-388. doi:10.1016/j.ydbio.2016.05.006

Spinelli SL, Malik HS, Consaul SA, Phizicky EM. 1998. A functional homolog of a yeast tRNA splicing enzyme is conserved in higher eukaryotes and in Escherichia coli. Proc Natl Acad Sci 95: 14136-14141. doi:10.1073/pnas.95.24.14136

Spinelli SL, Kierzek R, Turner DH, Phizicky EM. 1999. Transient ADP-ribosylation of a 2'-phosphate implicated in its removal from ligated tRNA during splicing in yeast. I Biol Chem 274: 2637-2644. doi:10.1074/jbc.274.5.2637

Steiger MA, Kierzek R, Turner DH, Phizicky EM. 2001. Substrate recognition by a yeast 2 '-phosphotransferase involved in tRNA splicing and by its Escherichia coli homolog. Biochemistry 40: 14098-14105. doi:10.1021/bi011388t
Steiger MA, Jackman JE, Phizicky EM. 2005. Analysis of 2'-phosphotransferase (Tptlp) from Saccharomyces cerevisiae: evidence for a conserved two-step reaction mechanism. RNA 11: 99-106. doi:10.1261/rna.7194605

Takahashi-Nakaguchi A, Matsumoto Y, Yamamoto M, Iwabuchi K, Totsuka Y, Sugimura T, Wakabayashi K. 2013. Demonstration of cytotoxicity against wasps by pierisin-1: a possible defense factor in the cabbage white butterfly. PLoS One 8: e60539. doi:10.1371/journal.pone.0060539

Takamura-Enya T, Watanabe M, Totsuka Y, Kanazawa T, Matsushima-Hibiya Y, Koyama K, Sugimura T, Wakabayashi K. 2001. Mono(ADP-ribosyl)ation of 2'-deoxyguanosine residue in DNA by an apoptosis-inducing protein, pierisin-1, from cabbage butterfly. Proc Natl Acad Sci 98: 12414-12419. doi:10.1073/pnas.221444598

Talhaoui I, Lebedeva NA, Zarkovic G, Saint-Pierre C, Kutuzov MM, Sukhanova MV, Matkarimov BT, Gasparutto D, Saparbaev MK, Lavrik OI, et al. 2016. Poly(ADP-ribose) polymerases covalently modify strand break termini in DNA fragments in vitro. Nucleic Acids Res 44: 9279-9295.

Tanabe M, Ishino Y, Nishida H. 2015. From structure-function analyses to protein engineering for practical applications of DNA ligase. Archaea 2015: 267570. doi:10.1155/2015/ 267570

Tanuma S, Sato A, Oyama T, Yoshimori A, Abe H, Uchiumi F. 2016. New insights into the roles of NAD+-poly (ADP-ribose) metabolism and poly(ADP-ribose) glycohydrolase. Curr Protein Pept Sci 17: 668-682. doi:10.2174/ 1389203717666160419150014

Till S, Ladurner AG. 2009. Sensing NAD metabolites through macro domains. Front Biosci 14: 3246-3258. doi:10.2741/3448

Timmons JA, Atherton PJ, Larsson O, Sood S, Blokhin IO, Brogan RJ, Volmar CH, Josse AR, Slentz C, Wahlestedt C, et al. 2018. A coding and non-coding transcriptomic perspective on the genomics of human metabolic disease. Nucleic Acids Res 46: 7772-7792. doi:10.1093/nar/gky570

Tucker JA, Bennett N, Brassington C, Durant ST, Hassall G, Holdgate G, McAlister M, Nissink JW, Truman C, Watson M. 2012. Structures of the human poly (ADP-ribose) glycohydrolase catalytic domain confirm catalytic mechanism and explain inhibition by ADP-HPD derivatives. PLoS One 7: e50889. doi:10.1371/journal.pone.0050889

Vanden Broeck D, Horvath C, De Wolf MJ. 2007. Vibrio cholerae: cholera toxin. Int J Biochem Cell Biol 39: 1771-1775. doi:10 .1016/j.biocel.2007.07.005

Voorneveld J, Rack JGM, Ahel I, Overkleeft HS, van der Marel GA, Filippov DV. 2018. Synthetic $\alpha$ - and $\beta$-Ser-ADP-ribosylated peptides reveal $\alpha$-Ser-ADPr as the native epimer. Org Lett 20: 4140-4143. doi:10.1021/acs.orglett.8b01742

Vyas S, Matic I, Uchima L, Rood J, Zaja R, Hay RT, Ahel I, Chang P. 2014. Family-wide analysis of poly(ADP-ribose) polymerase activity. Nat Commun 5: 4426. doi:10.1038/ncomms5426

Wang M, Yuan Z, Xie R, Ma Y, Liu X, Yu X. 2018. Structure-function analyses reveal the mechanism of the ARH3-dependent hydrolysis of ADP-ribosylation. I Biol Chem 293: 1447014480. doi:10.1074/jbc.RA118.004284

Waszkowycz B, Smith KM, McGonagle AE, Jordan AM, Acton B, Fairweather EE, Griffiths LA, Hamilton NM, Hamilton NS, Hitchin JR, et al. 2018. Cell-active small molecule inhibitors of the DNA-damage repair enzyme poly(ADP-ribose) glycohydrolase (PARG): discovery and optimization of orally bioavailable quinazolinedione sulfonamides. J Med Chem 61: 1076710792. doi:10.1021/acs.jmedchem.8b01407

Watanabe K, Kato J, Zhu J, Oda H, Ishiwata-Endo H, Moss J. 2018. Enhanced sensitivity to cholera toxin in female ADP- 
ribosylarginine hydrolase (ARH1)-deficient mice. PLoS One 13: e0207693. doi:10.1371/journal.pone.0207693

Welsby I, Hutin D, Gueydan C, Kruys V, Rongvaux A, Leo O. 2014. PARP12, an interferon-stimulated gene involved in the control of protein translation and inflammation. I Biol Chem 289: 26642-26657. doi:10.1074/jbc.M114.589515

Winstall E, Affar EB, Shah R, Bourassa S, Scovassi IA, Poirier GG. 1999. Preferential perinuclear localization of poly/ADP-ribose) glycohydrolase. Exp Cell Res 251: 372-378. doi:10 $.1006 /$ excr.1999.4594

Wu Z, Li Y, Li X, Ti D, Zhao Y, Si Y, Mei Q, Zhao P, Fu X, Han W. 2011. LRP16 integrates into NF- $\mathrm{kB}$ transcriptional complex and is required for its functional activation. PLOS One 6: e18157. doi:10.1371/journal.pone.0018157

Wu Z, Wang C, Bai M, Li X, Mei Q, Li X, Wang Y, Fu X, Luo G, Han W. 2015. An LRP16-containing preassembly complex contributes to NF- $\mathrm{KB}$ activation induced by DNA doublestrand breaks. Nucleic Acids Res 43: 3167-3179. doi:10 $.1093 / \mathrm{nar} / \mathrm{gkv} 161$

Xu Y, Cheah E, Carr PD, van Heeswijk WC, Westerhoff HV, Vasudevan SG, Ollis DL. 1998. GlnK, a PII-homologue: structure reveals ATP binding site and indicates how the T-loops may be involved in molecular recognition. I Mol Biol 282: 149165. doi:10.1006/jmbi.1998.1979

Yang J, Zhao YL, Wu ZQ, Si YL, Meng YG, Fu XB, Mu YM, Han WD. 2009. The single-macro domain protein LRP16 is an essential cofactor of androgen receptor. Endocr Relat Cancer 16: 139-153. doi:10.1677/ERC-08-0150

Yang CS, Jividen K, Spencer A, Dworak N, Ni L, Oostdyk LT, Chatterjee M, Kuśmider B, Reon B, Parlak M, et al. 2017. Ubiquitin modification by the E3 ligase/ADP-ribosyltransferase Dtx3L/Parp9. Mol Cell 66: 503-516.e5. doi:10.1016/j.molcel .2017 .04 .028
Zang L, Xue B, Lu Z, Li X, Yang G, Guo Q, Ba J, Zou X, Dou J, Lu J, et al. 2013. Identification of LRP16 as a negative regulator of insulin action and adipogenesis in 3T3-L1 adipocytes. Horm Metab Res 45: 349-358.

Zapata-Pérez R, Gil-Ortiz F, Martínez-Moñino AB, GarcíaSaura AG, Juanhuix J, Sánchez-Ferrer A. 2017. Structural and functional analysis of Oceanobacillus iheyensis macrodomain reveals a network of waters involved in substrate binding and catalysis. Open Biol 7: 160327. doi:10.1098/rsob .160327

Zarkovic G, Belousova EA, Talhaoui I, Saint-Pierre C, Kutuzov MM, Matkarimov BT, Biard D, Gasparutto D, Lavrik OI, Ishchenko AA. 2018. Characterization of DNA ADP-ribosyltransferase activities of PARP2 and PARP3: new insights into DNA ADP-ribosylation. Nucleic Acids Res 46: 24172431. doi:10.1093/nar/gkx1318

Zhang Y, Wang J, Ding M, Yu Y. 2013. Site-specific characterization of the Asp- and Glu-ADP-ribosylated proteome. Nat Methods 10: 981-984. doi:10.1038/nmeth.2603

Zhang H, Gu Z, Wu Q, Yang L, Liu C, Ma H, Xia Y, Ge X. 2015a. Arabidopsis PARG1 is the key factor promoting cell survival among the enzymes regulating post-translational poly(ADP-ribosyl)ation. Sci Rep 5: 15892. doi:10.1038/ srep 15892

Zhang W, Wang C, Song Y, Shao C, Zhang X, Zang J. 2015b. Structural insights into the mechanism of Escherichia coli YmdB: a 2'-O-acetyl-ADP-ribose deacetylase. I Struct Biol 192: 478486. doi:10.1016/j.jsb.2015.10.010

Zolkiewska A, Moss J. 1993. Integrin a 7 as substrate for a glycosylphosphatidylinositol-anchored ADP-ribosyltransferase on the surface of skeletal muscle cells. J Biol Chem 268: 2527325276. 


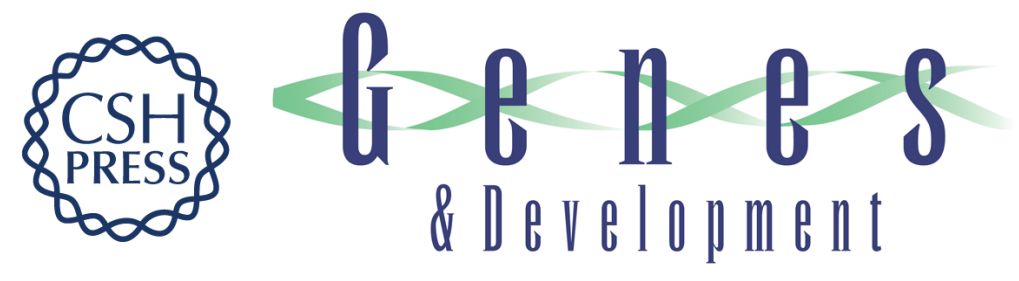

\section{(ADP-ribosyl)hydrolases: structure, function, and biology}

Johannes Gregor Matthias Rack, Luca Palazzo and Ivan Ahel

Genes Dev. 2020, 34: originally published online February 6, 2020

Access the most recent version at doi:10.1101/gad.334631.119

\section{Related Content}

References

Creative
Commons
License

Email Alerting

Service

\section{PARP and PARG inhibitors in cancer treatment}

Dea Slade

Genes Dev. March , 2020 34: 360-394 PARPs and ADP-ribosylation in RNA biology: from RNA expression and processing to protein translation and proteostasis Dae-Seok Kim, Sridevi Challa, Aarin Jones, et al.

Genes Dev. March , 2020 34: 302-320 The impact of PARPs and ADP-ribosylation on inflammation and hostpathogen interactions

Anthony R. Fehr, Sasha A. Singh, Catherine M. Kerr, et al.

Genes Dev. March , 2020 34: 341-359 Interplay between compartmentalized NAD+

synthesis and consumption: a focus on the PARP family

Michael S. Cohen

Genes Dev. March , 2020 34: 254-262 Nuclear PARPs and genome integrity

Kameron Azarm and Susan Smith

Genes Dev. March , 2020 34: 285-301 The role of ADP-ribose metabolism in metabolic regulation, adipose tissue differentiation, and metabolism

Magdolna Szántó and Peter Bai

Genes Dev. March , 2020 34: 321-340 PARPs and ADP-ribosylation: 60 years on

W. Lee Kraus

Genes Dev. March , 2020 34: 251-253

This article cites 211 articles, 62 of which can be accessed free at:

http://genesdev.cshlp.org/content/34/5-6/263.full.html\#ref-list-1

Articles cited in:

http://genesdev.cshlp.org/content/34/5-6/263.full.html\#related-urls

This article, published in Genes \& Development, is available under a Creative Commons License (Attribution 4.0 International), as described at

http://creativecommons.org/licenses/by/4.0/.

Receive free email alerts when new articles cite this article - sign up in the box at the top right corner of the article or click here.

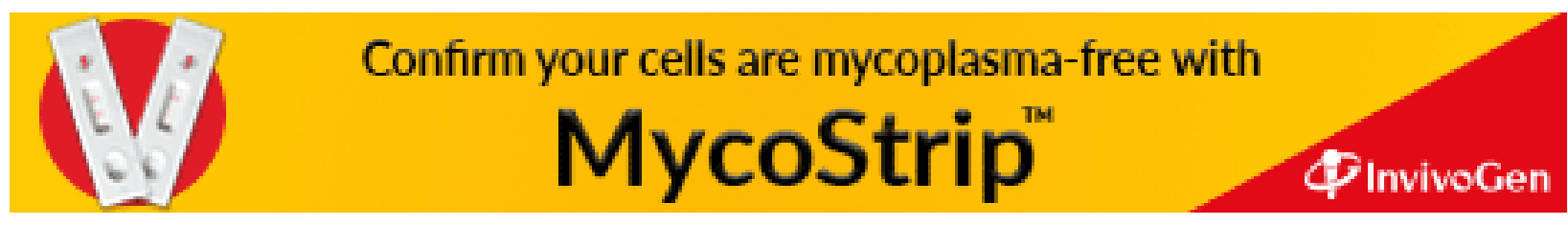

